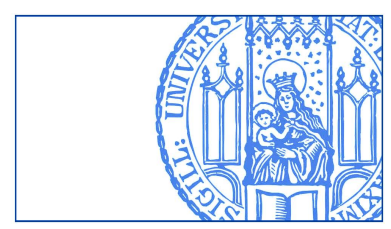

Flach, Lisandra und Irlacher, Michael:

\title{
Product versus Process
}

Munich Discussion Paper No. 2014-30

Department of Economics

University of Munich

Volkswirtschaftliche Fakultät

Ludwig-Maximilians-Universität München

Online at https://doi.org/10.5282/ubm/epub.21022 


\title{
Product versus Process: Innovation Strategies of Multi-Product Firms*
}

\author{
Lisandra Flach \\ University of Munich ${ }^{\dagger}$
}

\author{
Michael Irlacher \\ University of Munich ${ }^{\ddagger}$
}

June 25, 2014

\begin{abstract}
This paper studies the innovation strategies of multi-product firms in industries with different scope for product differentiation. In a simple model of multi-product firms, we show that returns to product versus process innovation are industry-specific. Demand and cost linkages induce a natural distinction between the returns to product and process innovation. In highly differentiated industries, the cannibalization effect is lower and, therefore, firms invest more in product innovation. In homogeneous industries, firms internalize intra-firm spillover effects and invest more in process innovation. We test the predictions from the model using Brazilian firm-level data, with information on investment efforts over time. Following a major exchange rate devaluation, firms have better access to foreign markets and exploit economies of scale in innovation. However, detailed information on product and process innovation allows us to evaluate differential effects across industries. We confirm the predictions from the theoretical model and show that the type of innovation depends on the industry scope for differentiation.
\end{abstract}

Keywords: Multi-Product Firms, Innovation, Product Differentiation, Cannibalization Effect, Spillovers, Globalization

JEL Classification: F12, F14, L25

\footnotetext{
${ }^{*}$ We are grateful to Carsten Eckel, Jennifer Poole, and participants at the Workshop "Internationale Wirtschaftsbeziehungen" in Goettingen and IO-Trade Seminar Munich for their helpful comments. Part of this paper was written while one of the coauthors (Lisandra Flach) was visiting the Brazilian Statistical Office (IBGE), whose support and hospitality is gratefully acknowledged. Felix Roellig provided excellent research assistance.

${ }^{\dagger}$ Department of Economics, D-80539 Muenchen, Germany; e-mail: lisandra.flach@econ.lmu.de.

${ }^{\ddagger}$ Department of Economics, D-80539 Muenchen, Germany; e-mail: michael.irlacher@econ.lmu.de.
} 


\section{Introduction}

Successful manufacturing firms continuously innovate to maintain their position in the market and to attend consumers' demand. Recent contributions in the international trade literature emphasize the importance of intra-firm adjustments through innovation in explaining welfare gains from trade liberalization, besides the well-established intra-industry gains from entry and exit of firms. This literature introduces innovation as a new dimension into the relationship between exporting and productivity: Better access to foreign markets leads to higher productivity through R\&D in more sophisticated manufacturing technologies. ${ }^{1}$ Consequently, innovation and productivity improvements within the firm account for a large fraction of productivity gains at the industry level. ${ }^{2}$ Moreover, variety-loving consumers benefit not only from new products of entering firms but first and foremost from product innovation by incumbent firms. ${ }^{3}$ Therefore, understanding innovation strategies and withinfirm adjustments of multi-product firms (MPFs) is crucial for the analysis of aggregate productivity and variety gains.

MPFs account for the majority of trade flows and are omnipresent in all industries. In terms of innovation activities, their investments account for a large fraction of aggregate changes in industry-level productivity and product variety (Bernard et al. (2010), Broda and Weinstein (2010), Lileeva and Trefler (2010), Bustos (2011)). However, with the exception of Dhingra (2013) (which is discussed later in detail), innovation in trade models happens only in one dimension, whereas in reality firms face a trade-off between investments in cost reduction and product variety. This raises the question of how and why firms in different industries make their choices between different types of innovation, with different implications in terms of welfare gains within industries.

The contribution of the paper is to investigate, theoretically and empirically, the innovation strategies of MPFs, focusing on within-firm adjustments. We evaluate a framework with demand and cost linkages in which firms face a trade-off between product and process innovation. Crucially, such linkages are only present in an MPF setting. Firms may decide

\footnotetext{
${ }^{1}$ Lileeva and Trefler (2010) as well as Bustos (2011) reveal that following a tariff cut firms increase their investments in technology. Lileeva and Trefler (2010) use tariff cuts associated with the US-Canadian free trade agreement and show that Canadian firms increased labor productivity and used more sophisticated manufacturing technologies. Furthermore, the access to a larger market induced firms to engage more in product innovation. For Argentinean firms, Bustos (2011) finds an increase in innovation expenditures by 0.20 to $0.28 \log$ points following the average reduction in Brazil's tariffs.

${ }^{2}$ Doraszelski and Jaumandreu (2013) show for Spanish firms that investments in R\&D are the primary source of productivity growth. Within sectors, between 65 percent and 90 percent of productivity growth arises through intra-firm productivity enhancing activities.

${ }^{3}$ Recent evidence of US bar code data in Broda and Weinstein (2010) highlights the importance of this channel. They show that at a four-year period, 82 percent of product creation happens within existing firms. Therefore only 18 percent of total household expenditure is on products of entering firms.
} 
to expand their product range or to lower production costs, and the net effect in terms of returns to innovation is a priori unclear.

In a simple model of MPFs, we show that returns to product and process innovation are industry-specific and uncover a mechanism related to the degree of product differentiation that explains this relation. On the one hand, by introducing new products firms internalize demand linkages, which may reduce demand for its own varieties. On the other hand, as a novel feature of our model, by investing in process innovation firms may internalize intrafirm spillover effects between production lines. To understand the role played by the degree of differentiation in this mechanism, consider two firms in sectors with different scope for product differentiation. A firm producing multiple products in a homogeneous industry has rather low returns from investing in new products as doing so may crowd out demand for its own products. This effect is known as the "cannibalization effect" in the literature. On the other hand, investments in process-optimizing technologies may generate a larger return, since the benefits from spillover effects across production lines are larger. With more similar production processes, the knowledge learned in the production process of more homogeneous products is applicable to a large fraction on the entire product portfolio. For firms in highly differentiated industries, the mechanism works exactly the other way round.

Our theoretical model builds on Eckel and Neary (2010) and Eckel et al. (2011). Each firm produces a bundle of products which are linked on the cost side by a flexible manufacturing technology. The latter captures the idea that - besides a core competence - MPFs can expand their portfolio with varieties that are less efficient in production. ${ }^{4}$ However, our theory introduces several novel features. First, we explicitly allow for two types of R\&D. Therefore, we assign fixed costs to additional products to model the decision on optimal scope closer to the notion of product innovation. Second, firms can invest in product-specific process innovation. Process innovation is costly and reflects economies of scale, such that firms invest more in optimizing technology of large-scale varieties close to their core competence. Third, another novel feature of our framework is to allow for spillover effects between the production processes within the firm. We relate the strength of these cost linkages to the degree of product differentiation in a sector. This occurs because products that are closer substitutes tend to have more similar production processes (in comparison to highly differentiated products).

Our framework has important implications for understanding how firms react to trade openness and to changes in market size. In particular, the model provides two main testable predictions. (1) We show that, following an increase in market size, firms invest more in inno-

\footnotetext{
${ }^{4}$ The idea that firms possess a core competency is also featured in models with MPFs by Arkolakis and Muendler (2010), Qiu and Zhou (2013), and Mayer et al. (2014).
} 
vation. As process innovation reflects economies of scale, access to a larger market promotes technology upgrading. Furthermore, access to larger markets reduce the perceived costs of product innovation, which encourages MPFs to extend their product scope. (2) However, in our framework, demand and cost linkages related to the degree of product differentiation determine returns to innovation. We show that in highly differentiated industries, the cannibalization effect is lower and, therefore, firms invest more in product innovation. In homogeneous industries, firms internalize higher intra-firm spillover effects and invest more in process innovation.

The predictions from the model are tested using detailed firm-level data, which has two distinctive features. First, we can exploit detailed information on innovation investments by firms in the period 1998-2000. Second, the event of a major and unexpected exchange rate devaluation in January 1999 provides an important source of exogenous variation. The currency devaluation made Brazilian products more competitive at home and abroad and, therefore, the shock may be interpreted as an increase in market size. Moreover, we are interested in how firms in different industries reacted to the exchange rate shock, in order to test prediction (2) from the model. To tackle this issue empirically, we use information on different types of innovation combined with the degree of differentiation of the industry.

Our empirical results reveal that firms increased their innovation efforts in both product and process innovation following the exchange rate devaluation. However, detailed information on the degree of differentiation and on the types of innovation conducted by firms allows us to evaluate differential effects across industries. Using a continuous measure of the degree of differentiation in an industry, we show that firms in more differentiated industries invest more in product innovation, while firms in more homogeneous industries invest more in process innovation. Our results are robust to different measures of the degree of differentiation, hold for different estimation strategies (we estimate the incidence of innovation using probit, linear probability model, and seemingly unrelated regression), and remain stable when adding several control variables.

Our paper is closely related to the literature on MPFs in international trade that features a cannibalization effect. ${ }^{5}$ Our theory builds on Eckel et al. (2011), who incorporate an endogenous investment in product quality in the framework by Eckel and Neary (2010). We abstract from investments in quality and instead focus on investments in product and process innovation. The paper that is closest in spirit to ours is Dhingra (2013), who also considers an innovation trade-off of MPFs. Dhingra (2013) proposes a model of MPFs with

\footnotetext{
${ }^{5}$ Eckel and Neary (2010) and Dhingra (2013) introduce cannibalization effects. However, this feature is not considered in many recent models of MPFs that assume monopolistic competition. One exception is the model proposed by Feenstra and Ma (2008).
} 
intra-brand cannibalization that induces a distinction between the returns to product and process innovation. Her framework explains how firms react to trade liberalization in terms of innovation investments. Following a trade liberalization, firms face higher competition from foreign firms and, therefore, reduce investments in product innovation to mitigate internal competition (cannibalization effect). On the other hand, firms increase investments in process innovation because of economies of scale. In contrast to her theoretical framework, we build a framework with demand and cost linkages to evaluate heterogeneous responses of firms in different industries. Moreover, using detailed firm-level data, we test the predictions from the model. In terms of the way we model innovation, the key differences between our paper and that of Dhingra (2013) are that we (1) allow for flexible manufacturing and (2) introduce cost linkages related to the degree of differentiation that generate spillover effects within the firm. Therefore, our model is able to generate novel predictions regarding the two types of innovation depending on the degree of differentiation of the industry.

Our paper is also related to the literature emphasizing the complementary between market size and innovation behavior of firms that leads to gains from trade. Since innovation is costly, changes in market size tend to encourage firms to incur these costs because of scale effects. Models such as Grossman and Helpman (1991) investigate the gains from trade arising from innovation investments in a setting with homogeneous firms. At the firm-level, several papers have investigated the relation between changes in market size and innovation. Lileeva and Trefler (2010) investigate theoretically and empirically how changes in market

size encouraged firms to innovate. Using responses of Canadian plants to the elimination of U.S. tariffs, they find that plants more induced by the tariff cuts increase more their investments in innovation. Yeaple (2005), Verhoogen (2008), Bustos (2011), and Aw et al. (2011) assess further channels that relate market size with firm-level innovation and within-firm adjustments.

\section{The Model}

Our theory draws on a simple model of MPFs that choose their optimal spending on product and process innovation. Both types of innovation are costly and, therefore, firms weight the returns to innovation against the costs. The returns to innovation are in the focus of this paper and constitute the main testable predictions from the model. First, we show that the returns to product and process innovation are higher in a larger market. Second, we point out that firms in sectors with homogeneous products focus on optimizing production processes while firms in more differentiated industries concentrate on innovating new products. These innovation patterns follow from demand and cost linkages, both related to the degree of 
product differentiation in a sector. Since these linkages determine the returns to innovation, we will introduce them at the very outset.

We begin with a detailed analysis of consumer behavior and the underlying preference structure in section 2.1. In this part, we show how the demand linkages enter our framework and relate them to the degree of product differentiation in a sector. In section 2.2, we present the firm side of the model. We start with the production cost function, which is characterized by flexible manufacturing. Moreover, firms can undertake investments in process innovation to reduce production costs of a product, which may generate spillovers between production lines. We refer to this feature as a cost linkage and argue that its strength decreases in the degree of product differentiation. Firms consider both linkages when maximizing their profits. Finally, section 2.3 derives the equilibrium of the model and establishes the main testable predictions from the theory.

\subsection{Consumer Behavior: Preferences and Demand}

Our economy consists of $L$ consumers who maximize their utility over the consumption of a homogeneous and a differentiated good. To be more specific, we assume that consumers buy a set $\Omega$ of goods out of a potential set $\widetilde{\Omega}$ of the differentiated product. Our specification of preferences follows Eckel et al. (2011), though we add an additional numeraire good and assume a quasi-linear utility in the following form: ${ }^{6}$

$$
U=q_{0}+u_{1}
$$

where $q_{0}$ is the consumption of the homogeneous good. We conduct our analysis in partial equilibrium where the outside good absorbs any income effects. Utility over the differentiated variety is defined in a standard quadratic function as follows

$$
u_{1}=a Q-\frac{1}{2} b\left[(1-e) \int_{i \in \widetilde{\Omega}} q(i)^{2} d i+e Q^{2}\right],
$$

where $a$ and $b$ represent non-negative preference parameters. In this specification, $q(i)$ denotes per variety consumption and $Q \equiv \int_{i \in \widetilde{\Omega}} q(i) d i$ stands for total consumption of the representative consumer. The parameter $e$ plays a very important role in our model and describes the degree of product differentiation. We assume that $e$ lies strictly between zero and one and define the parameter as an inverse measure for product differentiation. This means that lower values of $e$ imply more differentiated and hence less substitutable prod-

\footnotetext{
${ }^{6}$ The preferences in Eckel et al. (2011) capture an additional component adressing the utility which accrues from consuming goods of higher quality.
} 
ucts. Throughout the analysis, we will distinguish industries along the degree of product differentiation. We simply refer to a homogeneous industry as an industry with a relatively high value of $e$. Accordingly, a differentiated industry means an industry with a value of $e$ close to zero. A detailed discussion of the role of the parameter $e$ in our model will follow later on in the analysis.

Consumers maximize utility subject to the budget constraint $q_{0}+\int_{i \in \widetilde{\Omega}} p(i) q(i) d i=I$. Hence, individual income $I$ is spent on consumption of the outside good and the potential basket $\widetilde{\Omega}$ of the differentiated good. $p(i)$ is the price of variety $i$ and the numeraire good is sold at a price $p_{0}=1$. We assume that consumers demand a positive amount of the outside good $q_{0}>0$ to ensure consumption of the differentiated good. Maximizing utility and aggregating individual demand functions yields a linear market demand: ${ }^{7}$

$$
p(i)=a-b^{\prime}[(1-e) x(i)+e X]
$$

We define $\Omega \subset \widetilde{\Omega}$ as the subset of varieties which is actually consumed. $x(i)$ describes the market demand for variety $i$ and consists of the aggregated demand of all consumers $L q(i)$ for that specific variety. $X \equiv \int_{i \in \Omega} x(i) d i$ is the total volume of consumption of all differentiated goods. Furthermore, $a$ describes the demand intercept and $b^{\prime} \equiv \frac{b}{L}$ defines an inverse measure for the size of the market. Direct demand of variety $i$ is given by

$$
x(i)=\frac{a}{b^{\prime}(1-e+e \delta)}-\frac{1}{b^{\prime}(1-e)} p(i)+\frac{e \delta}{b^{\prime}(1-e+e \delta)(1-e)} \bar{p},
$$

where $\delta$ describes the measure of consumed varieties in $\Omega$. The average price of differentiated varieties in the economy is given by $\bar{p}=1 / \delta \int_{i \in \Omega} p(i) d i$.

As demand linkages will play a crucial role in our model, we conclude this section by analyzing how the degree of product differentiation affects the cross elasticity between any two varieties and the price elasticity of demand. The cross elasticity of variety $i$ with respect to variety $j$ is given by $\varepsilon_{i, j} \equiv|(\partial x(i) / \partial x(j))(x(j) / x(i))|=e x(j) /(1-e) x(i)$. It is straightforward to see that $\varepsilon_{i, j}$ is higher in more homogeneous sectors. For a firm this means: The closer is the substitutability between its varieties, the more does the output of any additional variety reduce the demand for the other products within its portfolio (i.e. the stronger are the demand linkages in a sector).

In addition to the cross elasticities, we also compute the price elasticity of demand to relate $e$ to our empirical measure of differentiation. The empirical part of the paper uses the Khandelwal (2010) classification as the preferred measure for product differentiation. This

\footnotetext{
${ }^{7}$ Given the quasi-linear upper-tier utility, there is no income effect, thereby implying that the marginal utility of income $\lambda=1$.
} 
measure is created by evaluating changes in prices conditional on market shares: A product is classified as more differentiated if the firm can increase prices without losing market shares. To connect this to our theoretical model, we compute the price elasticity of demand and show how it responds to a change in the degree of differentiation in a sector. Given the linear demand system in Eq. (3), there exists an upper bound of the price, where demand $x(i)$ is just driven to zero:

$$
p^{\max } \equiv \frac{(1-e) a+e \delta \bar{p}}{(1-e+e \delta)} .
$$

Following Melitz and Ottaviano (2008), we express the price elasticity of demand as

$$
\varepsilon_{i} \equiv\left|\frac{\partial x(i)}{\partial p(i)} \frac{p(i)}{x(i)}\right|=\frac{p(i)}{\left(p^{\max }-p(i)\right)},
$$

by combining Eqs. (4) and (5). Inspecting the latter expression clarifies the role of the degree of product differentiation $e$ in determining the demand linkages in our model. It can easily be shown that, ceteris paribus, the choke price $p^{\max }$ decreases and, therefore, the price elasticity $\varepsilon_{i}$ increases when products become more homogeneous.

$$
\left.\frac{\partial p^{\max }}{\partial e}\right|_{\bar{p}, \delta=c o n s t}=-\frac{\delta(a-\bar{p})}{(1-e+e \delta)^{2}}<0 .
$$

This implies that the parameter $e$ in our theoretical model is closely related to the Khandelwal (2010) measure of differentiation which we use in the empirical part of our paper.

\subsection{Firm Behavior: Optimal Product and Process Innovation}

In this section, we consider technology and optimal firm behavior. To keep the analysis as simple as possible, we rely on the monopoly case (since we focus on intra-firm adjustments, competition between firms plays only a second-order role). We construct a theoretical model in which MPFs optimally choose between two types of investment. Firstly, firms invest in new product lines and thereby extend their product portfolio. Secondly, firms may decide for each of their products how much to invest in the production technology. Both types of investment depend on the degree of product differentiation through the demand and cost linkages taken into account by a firm. In the previous section, we have already introduced the demand linkages into our model. We argue that the demand linkages in particular determine the returns to product innovation. While deciding on the optimal number of products, the firm considers the negative impact of the marginal good on the demand for the rest of its

products. Hence, the more similar are the products within the portfolio, the stronger will be the cannibalization effect of the marginal variety. Consequently, we show that the optimal 
product range will be smaller in a homogeneous sector.

As a novel feature of our model, we introduce cost linkages and relate them to the degree of product differentiation. In particular, the strength of the cost-linkages determines the returns to process innovation in our model. Firms may decide for each product how much to invest. However, we argue that there are intra-firm spillover effects between the varieties. This means that a firm can use parts of the process $R \& D$ of one product for other products in its portfolio. To which extent product-specific $\mathrm{R} \& \mathrm{D}$ is applicable to other processes depends on the similarity of production processes and, therefore, on the degree of product differentiation. Thus, firms in homogeneous sectors will invest more in process innovation as they can internalize more spillovers between production lines.

Production Technology Production is characterized by flexible manufacturing. We follow Eckel and Neary (2010) and assume that firms have a core competence $i=0$, which denotes the product where the firm is most efficient in production. Besides the core variety, an MPF can produce additional varieties with rising marginal costs. Production costs for variety $i$ without investments are given by $c(i)=c+c_{1} i$. For the sake of simplicity, we assume a linear cost function, though this is not required to derive our results.

Firms can reduce production costs through variety specific process innovation. Furthermore, we allow for investment spillovers between products. To reduce production costs of variety $i$, a firm undertakes process innovation $k(i)$ which reduces production costs at a diminishing rate. The variety specific costs savings from innovation are given by $2 k(i)^{0.5}$. As mentioned earlier, part of the process optimization of one variety is applicable to all other varieties, which implies that production of variety $i$ benefits from all investments undertaken on all the other products $K_{-i} \equiv \int_{\Omega \backslash i} k(i)^{0.5} d i$. The degree to which knowledge is applicable to other products depends on the spillover parameter $\theta(e) \in(0 ; 1)$. The spillover parameter $\theta$ depends on the degree of product differentiation $e$ because of the assumption that spillovers are larger in a more homogeneous sector. We will define a functional form for this parameter later on in the analysis.

Considering these aspects, production costs of variety $i$ are given by:

$$
c(i)=c+c_{1} i-\left(2 k(i)^{0.5}+2 \theta(e) K_{-i}\right) .
$$

This can be rearranged to

$$
c(i)=c+c_{1} i-\left(2(1-\theta(e)) k(i)^{0.5}+2 \theta(e) K\right),
$$

where in analogy to $X, K=\int_{0}^{\delta} k(i)^{0.5} d i$ denotes total investment in process innovation. 
Profit Maximization In our setup, an MPF simultaneously chooses optimal scale $x(i)$ and process innovation $k(i)$ per product as well as optimal product scope $\delta$. Process innovation is carried out at a rate $r_{k}$ and product innovation requires building a new production line at a rate $r_{\delta}$. Total profits are given by:

$$
\pi=\int_{0}^{\delta}\left[p(i)-c-c_{1} i+2(1-\theta(e)) k(i)^{0.5}+2 \theta(e) K\right] x(i) d i-\int_{0}^{\delta} r_{k} k(i) d i-\delta r_{\delta}
$$

Optimal Scale Maximizing profits in Eq. (10) with respect to scale $x(i)$ implies the following first-order condition: ${ }^{8}$

$$
\frac{\partial \pi}{\partial x(i)}=p(i)-c-c_{1} i+2(1-\theta(e)) k(i)^{0.5}+2 \theta(e) K-b^{\prime}(1-e) x(i)-b^{\prime} e X=0
$$

Using the inverse demand in Eq. (3) and solving for $x(i)$ yields optimal scale of variety $i$ :

$$
x(i)=\frac{a-c-c_{1} i+2(1-\theta(e)) k(i)^{0.5}+2 \theta(e) K-2 b^{\prime} e X}{2 b^{\prime}(1-e)} .
$$

Furthermore, we derive total firm scale $X$ by integrating over $x(i)$ in Eq. (12):

$$
X=\frac{\delta\left(a-c-c_{1} \frac{\delta}{2}\right)+2(1-\theta(e)+\theta(e) \delta) K}{2 b^{\prime}(1-e+e \delta)} .
$$

Inspection of Eq. (12) reveals the two opposing linkage effects arising from the degree of product differentiation in a sector. On the one hand, there is a demand linkage (cannibalization) of total firm's scale $X$ on the output of a single variety

$$
\frac{\partial x(i)}{\partial X}=-\frac{e}{1-e}<0
$$

whereby the negative impact increases in $e$. On the other hand, with rising values of $e$ the cost linkages (spillovers) from other varieties become more prominent:

$$
\frac{\partial x(i)}{\partial K}=\frac{\theta(e)}{b^{\prime}(1-e)}>0 .
$$

As a result of the underlying cost structure with flexible manufacturing, optimal scale of the core product is the largest, and output per variety diminishes with distance to the core product. We illustrate the output scheme in Figure 1 , where $\Delta^{0-\delta}$ indicates the difference in scale between the core and marginal product in the portfolio. The exact mathematical

\footnotetext{
${ }^{8}$ The second-order condition is negative: $\frac{\partial^{2} \pi}{\partial x(i)^{2}}=-2 b^{\prime}<0$.
} 
expression for $\Delta^{0-\delta}$ is determined later on in the analysis.

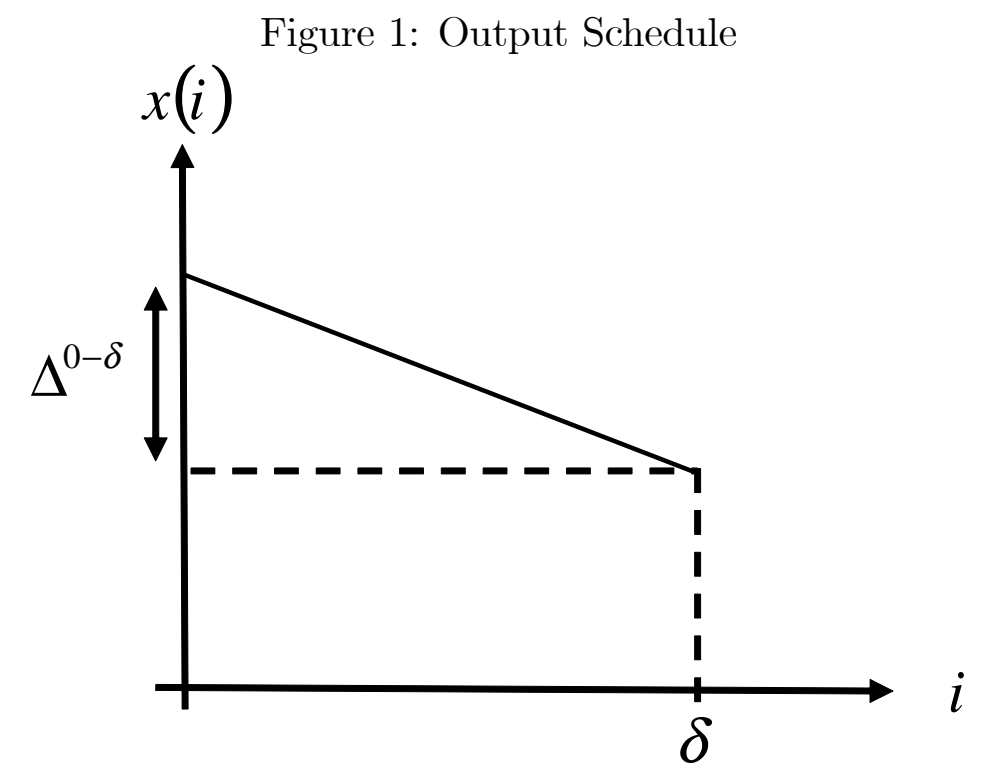

Substituting optimal scale in Eq. (12) into the inverse demand gives the optimal pricing schedule, with the lowest price charged for the core product:

$$
p(i)=\frac{1}{2}\left[a+c+c_{1} i-2(1-\theta(e)) k(i)^{0.5}-2 \theta(e) K\right] .
$$

The latter explains why the output of the core competency is sold at the highest scale. Finally, the price-cost margin for variety $i$ is given by:

$$
p(i)-c(i)=\frac{a-c-c_{1} i+2(1-\theta(e)) k(i)^{0.5}+2 \theta(e) K}{2} .
$$

Optimal Process Innovation Firms can invest in cost-reducing process innovation for each product in the portfolio. At the optimum, direct savings through lower production costs plus indirect savings from spillovers on other products are equal to the rate of innovation $\operatorname{costs} r_{k}$ :

$$
\frac{\partial \pi}{\partial k(i)}=(1-\theta(e)) k(i)^{-0.5} x(i)+\theta(e) k(i)^{-0.5} X-r_{k}=0
$$


Solving for optimal investments in variety $i$ yields: ${ }^{9}$

$$
k(i)=\left(\frac{(1-\theta(e)) x(i)+\theta(e) X}{r_{k}}\right)^{2} .
$$

Eq. (19) shows that optimal investment reflects economies of scale through both per variety output $x(i)$ and total firm output $X$. Given that the output of the core variety is the highest, a firm will put most effort in optimizing the production process of this variety. ${ }^{10}$ However, the first-order condition in Eq. (19) implies that the larger the spillovers $\theta(e)$ on other products within the firm, the more equally a firm spreads investments across products. In the extreme case of $\theta(e)=1$, investment levels are the same across products.

Lemma 1 Firms concentrate investments in process innovation on their core competencies, since process innovation reflects economies of scale. However, the investment levels across varieties become more similar in more homogeneous sectors due to higher spillover effects.

Finally, we substitute Eq. (12) into Eq. (19) and integrate over the expression. This gives total firm investment in process innovation

$$
K \equiv \int_{0}^{\delta} k(i)^{0.5} d i=\frac{(1-\theta(e))\left(\delta a-\delta c-c_{1} \frac{\delta^{2}}{2}\right)+2 b^{\prime}(\theta(e)-e) \delta X}{2\left(b^{\prime} r_{k}(1-e)-(1-\theta(e))(1-\theta(e)+\theta(e) \delta)\right)} .
$$

Optimal Product Innovation Choosing optimal product scope means balancing the benefits of the marginal variety against the innovation costs. The first-order condition for scope is given by:

$$
\frac{\partial \pi}{\partial \delta}=[p(\delta)-c(\delta)] x(\delta)+\left(-b^{\prime} e x(\delta)+2 \theta(e) k(\delta)^{0.5}\right) X-r_{k} k(\delta)-r_{\delta}=0,
$$

where $c(\delta)=c+c_{1} \delta-2(1-\theta(e)) k(\delta)^{0.5}-2 \theta(e) K$. In our framework with both cost and demand linkages, the marginal benefit of a product is determined by the negative externality on all other products (cannibalization) and the positive externality (spillovers in process innovation). ${ }^{11}$

$$
\underbrace{[p(\delta)-c(\delta)] x(\delta)}_{\text {Revenue }}+\{\underbrace{\left(-b^{\prime} e x(\delta)\right)}_{\text {Cannibalization }}+\underbrace{\left(2 \theta(e) k(\delta)^{0.5}\right)}_{\text {Spillover }}\} X=\underbrace{r_{\delta}+r_{k} k(\delta)}_{\text {Inn. Costs }}
$$

\footnotetext{
${ }^{9}$ The second-order condition is given by: $\frac{\partial^{2} \pi}{\partial k(i)^{2}}=-0.5\left(k(i)^{-1.5}(1-\theta(e)) x(i)+\theta(e) X\right)<0$, and is negative as required.

${ }^{10}$ Evidence for economies of scale at the product level can be found in Lileeva and Trefler (2010).

${ }^{11}$ The second-order condition is given by: $\frac{\partial^{2} \pi}{\partial \delta^{2}}=\left[-c_{1}-2\left(b^{\prime} e x(\delta)-2 \theta(e) k(\delta)^{0.5}\right)\right] x(\delta)<0$. To see that this condition is negative as required, consider Condition 1.
} 
In the decision to optimize the product range, an MPF takes into account that an additional product lowers the prices consumers are willing to pay for all other products. This aspect is captured by the term "Cannibalization" in Eq. (22). The term "Spillover" in Eq. (22) reflects the fact that there are spillovers from the marginal product on all other varieties. Hence, at this point it seems plausible to make a restriction on the parameter values which determines the net effect of the two linkages.

Condition 1 In Eq. (22), the net impact of the marginal variety on all other varieties is determined by the strength of the two linkages in our model. It is plausible to assume that the net impact of the marginal product on all varieties is negative. Therefore, we restrict the parameters as follows:

$$
b^{\prime} r_{k}>\frac{2 \theta(e)((1-\theta(e)) x(\delta)+\theta(e) X)}{e x(\delta)} .
$$

This condition implies that the perceived cost of process innovation may not be too low. We refer to $b^{\prime} r_{k}$ as the perceived costs of process innovation, as this term relates the market size to the innovation costs. Therefore, the perceived costs can fall (1) if $r_{k}$ decreases or (2) if the market size $L$ increases (recall that: $b^{\prime} \equiv \frac{b}{L}$ ). We argue that this restriction of parameters ensures realistic properties within our framework. If process innovation would be too "cheap", firms would increase product scope only to benefit from spillovers from the investment in the marginal variety. The latter does not seem to be a realistic optimal firm behavior.

In the following, we express a firm's optimal scope in terms of scale of the marginal product $x(\delta)$. To do so, we substitute the output of the marginal variety from Eq. (12) and its respective price-cost margin from Eq. (17) into the first-order condition for scope (21):

$$
x(\delta)=\sqrt{\frac{r_{k} k(\delta)+r_{\delta}-2 \theta(e) k(\delta)^{0.5} X}{b^{\prime}(1-e)}} .
$$

Considering again Figure 1, the latter expression can be interpreted as follows: The lower is the output of the marginal variety $\delta$, the larger is the product range offered by the firm.

To provide some further insights into our model, we combine the first-order conditions for scale and scope in Eqs. (12) and (24), to derive an alternative expression for optimal scale:

$$
x(i)=\frac{c_{1}(\delta-i)+2(1-\theta(e))\left(k(i)^{0.5}-k(\delta)^{0.5}\right)}{2 b^{\prime}(1-e)}+\sqrt{\frac{r_{k} k(\delta)+r_{\delta}-2 \theta(e) k(\delta)^{0.5} X}{b^{\prime}(1-e)}} .
$$


It is straightforward to see that this expression boils down to Eq. (24) by setting $i=\delta$ for the marginal variety. Furthermore, we can use this expression to calculate the difference in scale of the core $(i=0)$ versus the marginal variety $\delta$, illustrated in Figure 1:

$$
\Delta^{0-\delta}=\frac{c_{1} \delta}{2\left(b^{\prime}(1-e)-\frac{(1-\theta(e))^{2}}{r_{k}}\right)} .
$$

Since the underlying technology is flexible manufacturing, the difference in output increases in the product range $\delta$. The larger is the distance to the core product, the lower will be the efficiency of the marginal product. The latter effect is magnified for higher values of $c_{1}$, as this variable determines how much marginal costs increase with rising distance to the core product. Moreover, $\Delta^{0-\delta}$ decreases in the strength of the spillovers $\theta(e)$. As stated in Lemma 1, firms concentrate their investment in process R\&D on the core varieties. However, if spillover effects are large, the marginal varieties benefit more from the investments in the high-scale core varieties.

Lemma 2 The difference in scale between the core and the marginal variety is determined by the difference in production costs of the two varieties. The productivity of the marginal product falls with distance to the core product and rises in the degree of spillovers.

\subsection{Comparative Statics}

In the previous section, we established the baseline theoretical framework. In the next step, we derive the main predictions that we test in the empirical section. To start with, we analyze the effects of an increase in the market size $L$ (lower values of $b^{\prime}$ ) on optimal investment levels. Furthermore, we investigate optimal investment strategies in sectors with different degrees of product differentiation. To derive our results, we follow the solution path in Eckel and Neary (2010), and express the equilibrium equations in terms of $X$ and $\delta$ only. Moreover, as already mentioned, we define a functional form for the spillover parameter $\theta(e)$ :

$$
\theta(e)=e^{\kappa}
$$

Figure 2 illustrates this functional form and the role of $\kappa$ in determining the strength of spillovers. Since $e \in[0,1]$, lower values of $\kappa$ translate into a stronger spillover effect. In the extreme case of $\kappa=0$, the total investment in one variety is applicable on all varieties within the firm. Obviously, we derive the same result in an industry with no product differentiation (i.e. $e=1$ ). Letting $\kappa$ grow large decreases the importance of spillovers within the firm. 


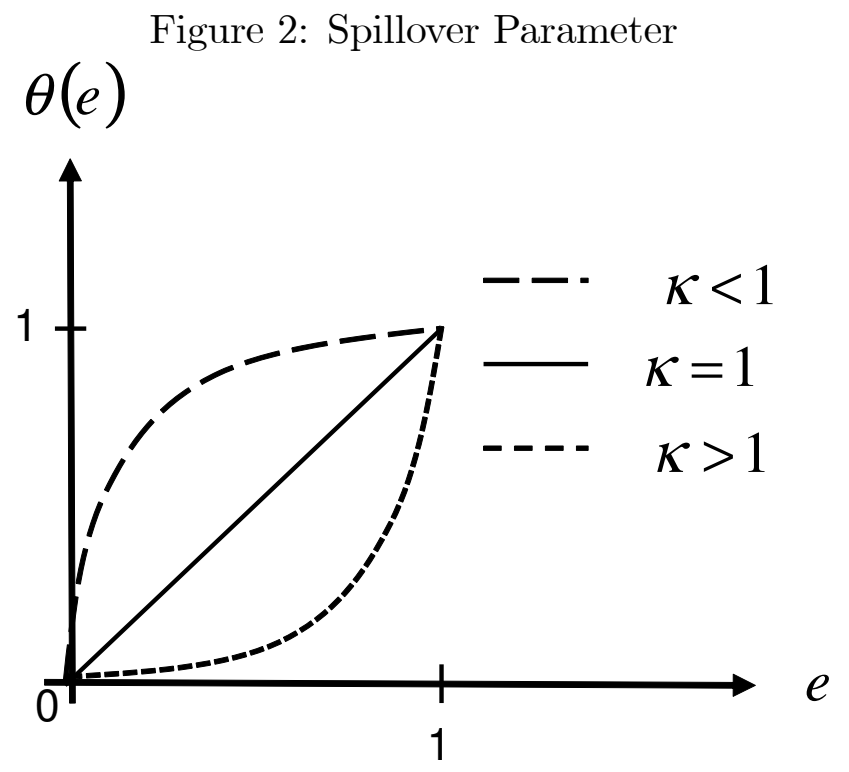

Equilibrium In this section, we derive the equilibrium equations of the model applying the functional form of spillovers in Eq. (27). Combining Eqs. (13) and (20), we derive total firm scale as:

$$
X=\frac{\delta\left(a-c-c_{1} \frac{\delta}{2}\right)}{2\left(b^{\prime}(1-e+e \delta)-\frac{\left(1-e^{\kappa}+e^{\kappa} \delta\right)^{2}}{r_{k}}\right)} .
$$

The term $\frac{\left(1-e^{\kappa}+e^{\kappa} \delta\right)^{2}}{r_{k}}$ reflects cost-savings from process innovation, which induces a firm to increase total firm scale $X$. Clearly, the strength of the latter effect is mitigated by the costs for process innovation $r_{k}$. Plugging Eq. (28) back into Eq. (20) yields total process innovation as:

$$
K=\frac{\left(1-e^{\kappa}+e^{\kappa} \delta\right)}{r_{k}} X .
$$

The parameter $\kappa$ determines the strength of spillovers, where total process innovation is the largest for $\kappa=0$. Inspecting Eqs. (28) and (29) in detail reveals that investments in process innovation decrease with rising levels of $\kappa$, i.e. $\frac{\partial K}{\partial \kappa}<0$. Furthermore, process innovation $K$ reflects economies of scale as it depends on total firm scale $X$. Using information from Eqs. (19), (28), and (29) together with Eq. (12), we can express optimal scale per variety as:

$$
x(i)=\frac{a-c-c_{1} i-2\left(b^{\prime} e-\frac{e^{\kappa}\left(2\left(1-e^{\kappa}\right)+e^{\kappa} \delta\right)}{r_{k}}\right) X}{2\left(b^{\prime}(1-e)-\frac{\left(1-e^{\kappa}\right)^{2}}{r_{k}}\right)} .
$$


Within our framework, we have two opposing effects of total scale $X$ on per variety output. On the one hand, rising total output induces the firm to invest more in process innovation, which increases per variety output. On the other hand, rising total scale intensifies cannibalization within the portfolio. The latter effect reduces per variety output. However, Condition 1 stated in Eq. (23) guarantees that the spillover effect cannot dominate the cannibalization effect, i.e. $\frac{\partial x(i)}{\partial X}<0$.

Finally, substituting from Eq. (19) into Eq. (24), we express the first-order condition for scope as:

$$
x(\delta)=\sqrt{\frac{r_{\delta}-\frac{\left(e^{\kappa} X\right)^{2}}{r_{k}}}{\left(b^{\prime}(1-e)-\frac{\left(1-e^{\kappa}\right)^{2}}{r_{k}}\right)}} .
$$

The formal derivation of this expression is presented in the Appendix. Eq. (31) implicitly defines product scope $\delta$ in terms of the output of the marginal variety. Solving for $\delta$ gives the explicit expression for product scope:

$$
\delta=\frac{a-c-2 \sqrt{\left(b^{\prime}(1-e)-\frac{\left(1-e^{\kappa}\right)^{2}}{r_{k}}\right)\left(r_{\delta}-\frac{e^{2 \kappa} X^{2}}{r_{k}}\right)}-2\left(b^{\prime} e-\frac{2 e^{\kappa}\left(1-e^{\kappa}\right)}{r_{k}}\right) X}{\left(c_{1}-\frac{2 e^{2 \kappa} X}{r_{k}}\right)} .
$$

Eqs. (31) and (32) reveal that higher costs for product innovation $r_{\delta}$ decrease the optimal product range. The latter implies a higher output of the marginal variety $\delta$ (see Eq. (31)). Referring to Figure 1, this characterizes a variety closer to the firm's core competence. Inspecting the term $2 \sqrt{\cdot}$ in Eq. (32) reveals the multiplicative structure of the inverse measure for market size $\left(b^{\prime} \equiv \frac{b}{L}\right)$ and the cost for product innovation $r_{\delta}$. This structure translates an increase in the market size $L$ into lower perceived costs of product innovation for the firm.

Inspecting the previous equations indicates that the equilibrium in our model can be characterized in terms of two endogenous variables: $\delta$ and $X$. In Figure 3, Eq. (28) is labeled by "Scale: $X(\delta)$ " and describes a positive relationship between total firm output $X$ and scope $\delta$. Through adding additional products, an MPF can increase its total output. Eq. (32) establishes a negative relationship between $X$ and $\delta$. The downward-sloping curve "Scope: $\delta(X)$ " illustrates that rising firm output intensifies the cannibalization effect of the marginal variety. Therefore, an MPF reduces its product scope when its total output increases. In the intersection of both curves in Figure 3, the two equilibrium conditions for scale and scope are satisfied. ${ }^{12}$ Once we have determined the equilibrium values of $\delta$ and $X$,

\footnotetext{
${ }^{12} \mathrm{~A}$ proof that the two curves intersect is provided in the Appendix. We show that the determinant of the coefficient matrix is always positive. This ensures that the equilibrium is unique and stable.
} 
Figure 3: Equilibrium

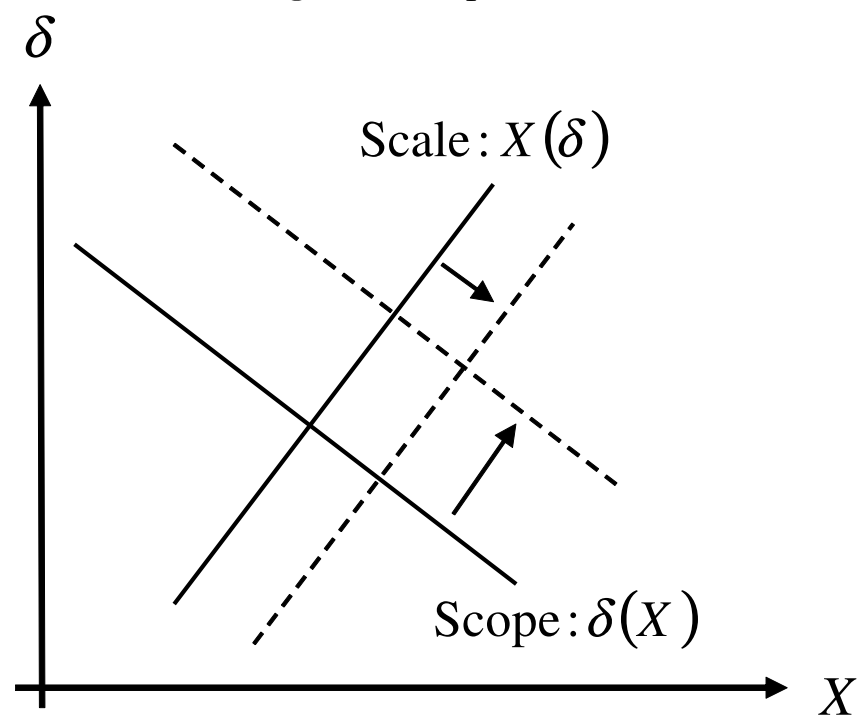

we compute the equilibrium value of process innovation $K$. In the next step, we derive the main testable predictions from the model.

The Effects of a Larger Market Size We are interested in the effects of globalization on product and process innovation. We follow Krugman (1979) and interpret globalization as an increase in the number of consumers $L$. As we analyze the behavior of a single MPF, we neglect the competition effect of globalization. This modeling choice is motivated by the nature of our empirical analysis, where we investigate the effect of a devaluation of the Brazilian real. For Brazilian exporters, a devaluation means improved access to foreign markets since products become cheaper. Therefore, Brazilian firms can gain foreign market shares without losing domestic market shares.

An increase in the market size $L$ reduces the slope $b^{\prime}$ of the demand function in Eq. (3). In the Appendix, we derive the total derivatives of the equilibrium conditions in terms of scale $X$ (Eq. (28)) and scope $\delta$ (Eq. (32)), which lead to the following results.

We show that increases in the market size lead to higher total firm output $X$. Three different intra-firm adjustments lead to this result. The first adjustment comes from the increased demand in the larger market. The second and third adjustments come from the impact of product and process innovation on total firm scale $X$. We show that despite cannibalization is intensified through the larger $X$, a firm will invest in new products in a larger market. In Figure 3, both curves "Scale: $X(\delta)$ " and "Scope: $\delta(X)$ " are shifted to the right, though "Scope: $\delta(X)$ " shifts more. The cannibalization effect of increasing firm scale $X$ on scope $\delta$ can be visualized by comparing the product range before and after the shift of 
"Scale: $X(\delta)$ ". Technically the increase in product scope is caused by the fact that in Eq. (32) the costs for product innovation $r_{\delta}$ enter multiplied by the parameter $b^{\prime}$. As explained earlier in the text, a larger market size reduces the perceived innovation costs for the firm. Finally, we analyze the impact of the market size on process innovation $K$. As discussed earlier, process innovation is subject to economies of scale as in a larger market innovation costs can be spread over more units. From inspection of Eq. (29), we see that the rise in $\delta$ and $X$ causes more spending in process innovation. Captured by the term $\frac{\left(1-e^{\kappa}+e^{\kappa} \delta\right)^{2}}{r_{k}}$ in Eq. (28), the process innovation effect contributes to the rise in firm scale $X$. We summarize the market size effect on optimal firm behavior in the following proposition and test these results in the empirical part of the paper.

Proposition 1 A larger market size L increases total scale $X$ and induces firms to invest more in both product $\delta$ and process innovation $K$, i.e.

$$
\frac{d \ln X}{d \ln L}>0, \frac{d \ln \delta}{d \ln L}>0, \text { and } \frac{d \ln K}{d \ln L}>0 .
$$

The mathematical derivation of these results is presented in the Appendix. Furthermore, we show the effects of a change in the demand intercept $a$ on the optimal behavior of the firm. The latter comparative static yields qualitatively the same results.

Sectors with Different Scope for Product Differentiation We derive a second testable prediction of our model with respect to the degree of product differentiation in a sector. A simple comparison between brick production and the automotive sector makes it clear that there is a lot more scope for differentiation in the latter sector. We argue that the degree of differentiation is crucial in explaining the innovation behavior of firms. Recall, that degree of differentiation determines the strength of the two linkages within our framework. A low degree of differentiation (high e) causes high cannibalization and high spillover effects and, therefore, promotes process innovation. One can think again of our example of an MPF producing bricks that are slightly differentiated. It is plausible to assume that a large fraction of the investment in the production line of one specific brick is applicable to the production of all other bricks produced by the same firm. However, introducing one further brick will have a strong cannibalizing impact on the initial portfolio. Differentiating Eq. (29) with respect to the degree of product differentiation $e$ keeping firm size fixed confirms our intuition:

$$
\frac{\partial \ln K}{\partial \ln e}=\frac{\kappa e^{\kappa}(\delta-1)}{\left(1-e^{\kappa}+e^{\kappa} \delta\right)}>0 .
$$

Let us now assume the other extreme case of a highly differentiated industry, in our 
example the automotive sector. Assuming that cars are more differentiated than bricks, optimizing the production process for one specific car will have positive but lower spillovers on the other cars in comparison to the case of (more homogeneous) bricks. The more differentiated two cars are, the lower will be the number of identical parts used in production and, therefore, the lower will be the spillovers in production. However, for a firm producing multiple cars, the negative externality of adding an additional car declines the higher is the degree of differentiation (i.e. the lower is the cannibalization effect). Again, we hold firm size fixed and differentiate Eq. (32) with respect to the degree of product differentiation $e$. There are two opposing channels at work when considering the effect of the degree of product differentiation on the product range $\delta$. On the one hand, the marginal product cannibalizes, on the other hand, all initial products benefit from process-spillovers from the marginal product. Differentiating Eq. (32) with respect to $e$ leads to a cumbersome expression, which is presented in the Appendix. Here we show the solution for the case of the strongest spillover effects. The following derivative reveals that even in this case the cannibalization effect dominates, which confirms our intuition.

$$
\lim _{\kappa \rightarrow 0} \frac{\partial \ln \delta}{\partial \ln e}=-\frac{b^{\prime} e(2 X-x(\delta))}{\left(c_{1}-\frac{2 X}{r_{k}}\right) \delta}<0
$$

The derivation of this expression and further discussion are presented in the Appendix.

We summarize the effect of the degree of product differentiation on optimal innovation behavior in the following proposition and test the results in the empirical part of the paper.

Proposition 2 Conditional on firm size, firms in sectors with a large (low) scope for product differentiation will invest more in product (process) innovation. This behavior is caused by the lower (stronger) demand-and lower (stronger) cost-linkages in a differentiated (homogeneous) sector.

\section{Data}

We test the main predictions of the model using Brazilian firm-level data for the period 1998-2000. Firm-level data are matched using the unique firm tax number and come from two main sources: (i) SECEX (Foreign Trade Secretariat), which provides information on the universe of products exported by Brazilian firms and (ii) Innovation survey from PINTEC (Brazilian Firm Industrial Innovation Survey). We combine firm-level data with industrylevel data to investigate how different industries react to a trade shock in terms of their investments in innovation. 
A distinctive feature of the data is the availability of highly detailed information on firmlevel innovation investments, including several dimensions of product and process innovation. A further distinctive feature of the data is the event of a major and largely unexpected exchange rate shock in the period under analysis. The devaluation made Brazilian products more competitive in both domestic and foreign markets and, therefore, increased incentives for firms to innovate (due to scale effects). However, firms react in different ways to the trade shock depending on the degree of product differentiation of the industry: While more homogeneous industries have higher incentives to invest more in process innovation because of spillover effects, differentiated industries have higher incentives to invest in product innovation because of lower cannibalization across products. To tackle this issue, we use information on different types of innovation combined with the degree of product differentiation of the industry.

\subsection{Innovation Variables}

The innovation survey provides detailed information on innovation investments of 3,070 manufacturing exporters for which we can exploit time-varying information. ${ }^{13}$ The main questions used in our study for product and process innovation are: 1. Did the firm introduce a new product in the period? (product innovation) and 2. Did the firm introduce new production processes in the period? (process innovation). For changes in product, we create a variable $\Delta$ Product $_{f}=1$ if a firm $f$ in industry $i$ reported important efforts to do product innovation. For changes in process we create a variable $\Delta$ Process $_{f}=1$ if the firm reported changes in process.

Product innovation does not necessarily mean an increase in product scope (suggested by our theory), since firms could simultaneously add and drop varieties or change the attributes of existent varieties. Therefore, in order to get closer to our theoretical mechanism, we use a further question from the survey related to product scope: 3. Importance of the innovation to increase product scope, $\Delta S_{\text {cope }}$. This categorical variable (with four degrees of importance) relates innovation to changes in product scope.

For process innovation, the variable $\Delta$ Process $s_{f}$ may also not be directly related to the mechanism we propose in the theory (that some firms internalize spillover effects and, therefore, invest more in process innovation). Thus, to evaluate the importance of spillover effects, we use information related to changes in the flexibility of the production process. In particular, we use the following question from the survey: 4. Importance of the innovation to increase production flexibility, $\Delta$ Flexibility $_{f} . \Delta$ Flexibility $_{f}$ is a categorical variable (with

\footnotetext{
${ }^{13}$ The PINTEC (2000) survey provides information for a total of 3,700 firms. However, for 630 of them information for many variables of interest is only available for the year 2000 .
} 
four degrees of importance) related to the ability of the firm to make the production process more flexible and increase the spillover effects among production lines. Therefore, it is consistent with the mechanism of the theoretical model, predicting that firms may internalize intra-firm spillover effects. The description of variables is found in Table 14 in the Appendix.

The data has the disadvantage of not capturing differences in the intensity of innovation across firms (variables are at most categorical, but not continuous). However, for the purposes of our study, we are able to capture the relevant mechanism, referring to the variation in innovation efforts across industries.

Table 1 presents summary statistics for the baseline indicators of innovation. ${ }^{14}$ About half of the firms reported changes in process and 42 percent changes in product. ${ }^{15}$ The interest of the study is to provide more information on the innovation choices of firms in different industries.

Table 1: Percentage of Firms by Innovation Status in the Year 2000

\begin{tabular}{lll}
\hline Product innovation & $\begin{array}{l}\text { Process innovation } \\
42 \%\end{array}$ & $\begin{array}{l}\text { Product and process innovation } \\
48 \%\end{array}$ \\
\hline
\end{tabular}

\subsection{Degree of Product Differentiation}

For the analysis across firms, we create measures of the degree of product differentiation across sectors $\left((1-e)_{s}\right.$, for a sector $\left.s\right)$. For that, we match the firm-level innovation survey with information on the degree of product differentiation using (1) the Khandelwal (2010) classification of product differentiation and (2) the Rauch (1999) classification of goods, as follows:

Khandelwal (2010) Classification of Product Differentiation Khandelwal (2010) classifies sectors and products according to the degree of product differentiation and characterizes products as long and short "quality ladders". The paper uses nested logit estimations to infer product quality from price and quantity information of products exported to the United States: The quality of a product increases if its price can rise without losing market share. Quality ladders for each product are constructed from estimated qualities, calculated as the difference between the maximum quality $\left(\lambda_{p}^{M A X}\right)$ and minimum quality $\left(\lambda_{p}^{M I N}\right)$ within

\footnotetext{
${ }^{14}$ Values are based on a sample of 3,070 firms, for which we can exploit time-varying information (sample used in the paper).

${ }^{15} 42$ percent of firms conducted product innovation and 14 percent reported only product innovation (no process innovation). 48 percent of firms conducted process innovation and 20 percent only process innovation. 28 percent of the firms reported both product and process innovation.
} 
a product $p$, as follows: $\lambda_{p}=\lambda_{p}^{M A X}-\lambda_{p}^{M I N}$. In this specification, $\lambda_{p}$ denotes the difference between the minimum and maximum of the estimated quality $\lambda_{p c t}$ of country $c$ 's exports to the United States at time $t$ in product $p$. The higher $\lambda_{p}$, the higher the degree of product differentiation, such that the variation in market shares conditional on product prices is higher. Therefore, the mechanism proposed by Khandelwal (2010) is closely related to the mechanism we derive in the theory section (see Eqs. (6) and (7)).

We use the Khandelwal (2010) product classification of the ladder length available at the 4-digit SIC1987 classification. This measure is mapped to the 2-digit IBGE classification of sectors and industries and generates a ladder length $\lambda_{s}$, as the average ladder over all products exported in sector $s$.

Rauch (1999) Classification of Goods Rauch (1999) classifies trade data into three groups of commodities: w, homogeneous (organized exchange) goods, which are goods traded in an organized exchange; $\mathbf{r}$, reference priced goods, not traded in an organized exchange, but which have some quoted reference price, such as industry publications; and $\mathbf{n}$, differentiated goods, without any quoted price. Using this classification at the 4-digit SITC product classification (issued by the United Nations), we create a measure of the share of products from a firm classified as differentiated goods: ShDif $f_{s}=\frac{\text { Nproducts }_{s, n}}{\text { Nproducts }_{s,(w+r+n)}}$, where $\operatorname{ShDiff} f_{s}$ is the share of products produced by sector $s$ classified as differentiated goods. Also in this case, we map the Rauch (1999) classification of goods to the 2-digit industry classification of differentiation from IBGE. Moreover, as an alternative measure, we estimate ShSales $_{s}=$ $\frac{\text { Sales }_{n}}{\operatorname{TotalSales}_{(w+r+n)}}$, where ShSales is the share of sales of differentiated products in comparison to total sales in a sector $s .^{16}$

We use $\lambda_{s}$ as our benchmark measure, since $\lambda_{s}$ provides higher variation in comparison to ShDiff $f_{s}$. While $\lambda_{s}$ is created from a continuous variable (product ladder), the Rauch (1999) classification is created from a binary variable (products classified as differentiated or non-differentiated goods). Thus, ShDiff $f_{s}$ may be inaccurate and subject to measurement error. We keep the Rauch (1999) classification for robustness checks. Summary statistics for both measures of differentiation are shown in Table 2.

Table 2: Degree of Product Differentiation by Industry

\begin{tabular}{lccccc}
\hline Measures of $(1-e)_{s}$ & Observations & Mean & Std. Deviation & Min & Max \\
\hline$\lambda_{s}$ & 3,070 & 1.73 & 0.21 & 1.10 & 2.27 \\
ShDiff & 3,070 & 0.73 & 0.12 & 0.33 & 1 \\
\hline
\end{tabular}

\footnotetext{
${ }^{16}$ However, we believe that the share of differentiated products measured by the number of products

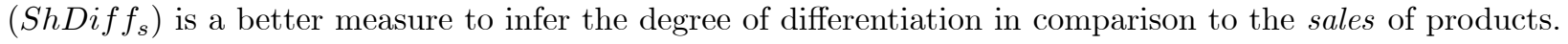
Estimations using the share of sales $\left(\right.$ ShSales $\left._{s}\right)$ remain significant (results available upon request).
} 


\subsection{Industry-specific Exchange Rates}

In January 1999, the Brazilian government announced the end of the crawling peg, allowing the real to free float, with a consequent depreciation of the real by 25 percent (within a month). Figure 4 shows the evolution of the exchange rate in this period. While the size of the devaluation did not vary across different bilateral currencies, it varied across industries depending on the degree of openness to trade of the industry. We exploit the variation across time in exchange rates for industries with different degrees of exposure to global markets using trade-weighted industry-specific exchange rate shocks. In this way, we can empirically test the theoretical prediction that firms innovate more following an increase in market size (an increase in $L$ in the model). Crucially, since all firms in our sample are permanent exporters, we expect them to react to the shock in a similar way.

Figure 4: Monthly Real Exchange Rates for Brazil, 1996-2001

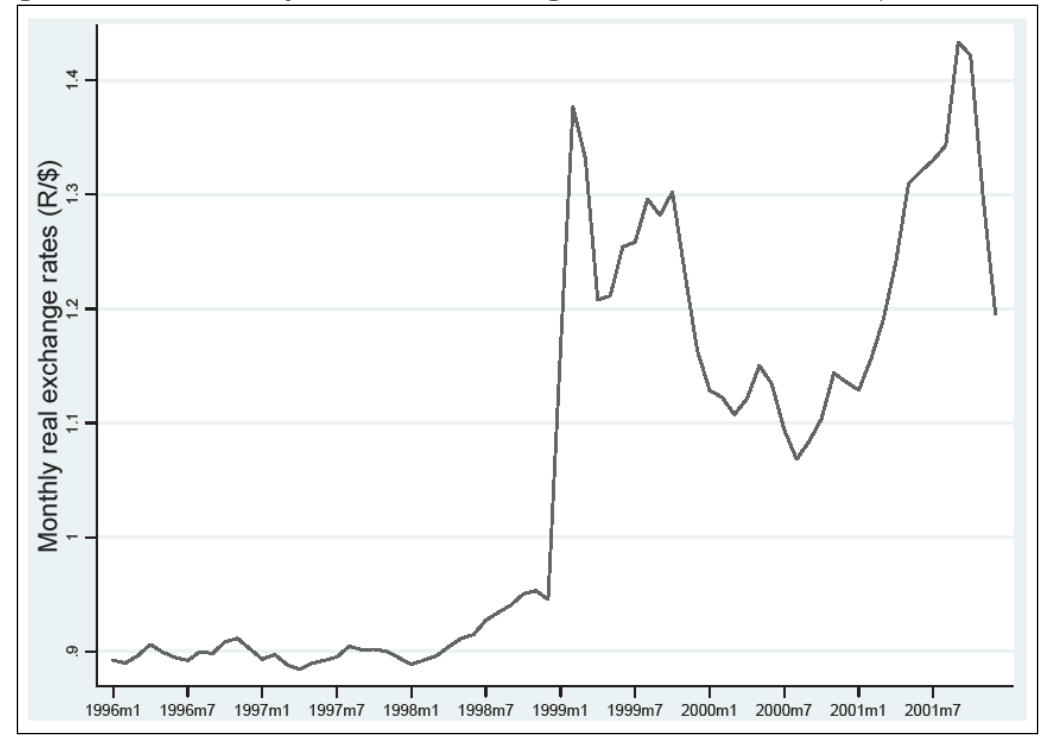

Industry-specific exchange rates are constructed using yearly bilateral trade data from NBER-UN coded by Feenstra et al. (2005) and bilateral exchange rate data from the International Monetary Fund. The underlying idea of the industry-specific exchange rate shock is to study how the movements in different bilateral exchange rates with respect to the real affected different industries, depending on how much they trade with other countries. The bilateral trade data from NBER-UN provides information on bilateral trade flows at the 4-digit SITC level. The SITC classification is combined with the Brazilian CNAE industry classification using publicly available concordance tables up to 4-digit CNAE. ${ }^{17}$ Following

\footnotetext{
${ }^{17}$ Concordance tables are publicly available at:

http://econweb.ucsd.edu/muendler/html/brazil.html\#brazsec.
} 
Goldberg (2004) and Almeida and Poole (2013), we calculate the industry-specific exchange rates as follows:

$$
T R E R_{i t}=\sum_{c}\left(\left(0.5 \frac{X_{i c t}}{\sum_{c} X_{i c t}}+0.5 \frac{M_{i c t}}{\sum_{c} M_{i c t}}\right) * r e r_{c t}\right)
$$

where $i$ is industry, $c$ is country, and $t$ is time, such that the bilateral real exchange rate $r e r_{c t}$, measured by the Brazilian currency real with respect to the trading partner $c$, is weighted by the industry-specific trade shares. The industry-specific shares are time-varying import shares $\left(\frac{M_{i c t}}{\sum_{c} M_{i c t}}\right)$ and export shares $\left(\sum_{c}^{X_{i c t}}\right)$ by industry and bilateral country pair.

Figure 5 shows the trade-weighted industry-specific exchange rates for firms above and below the mean of product differentiation (high or low mean $\lambda_{s}$ ). Two important facts must be mentioned. First, Figure 5 illustrates a substantial heterogeneity across industries in the trade-weighted exchange rates. Second, the figure shows that in both groups of firms/industries the distribution of $T R E R_{i t}$ is very similar, implying that there is no clear correlation between the degree of product differentiation and the openness of the industry.

Figure 6 in the Appendix reports changes in trade-weighted exchange rates over time. The right and left panels reveals that changes in $T R E R_{i t}$ are similar for both groups of industries (with high and low degree of differentiation, according to the Khandelwal (2010) classification).

Figure 5: Industry Variation in Trade-weighted Real Exchange Rates for Firms in Industries with High and Low Degrees of Product Differentiation

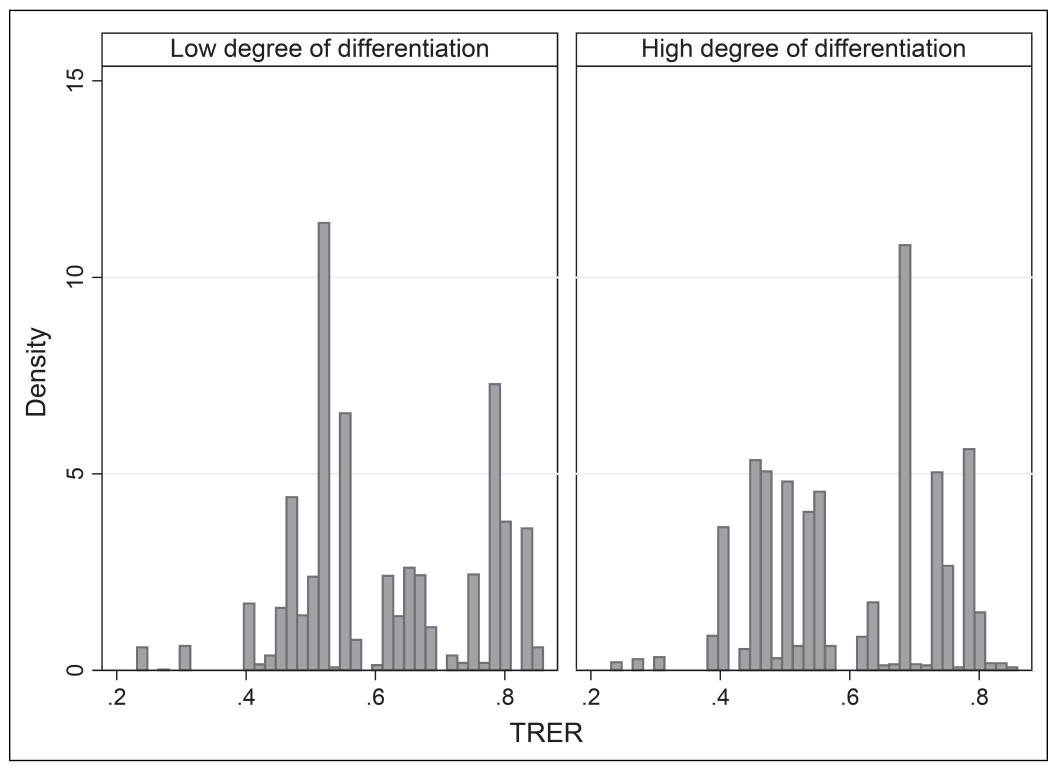




\subsection{Correlation between the Main Variables of Interest}

The theoretical model predicts that firms in more differentiated industries will do more product and less process innovation in comparison to less differentiated industries. Table 3 shows the correlation between the innovation variables and our main variables for the degree of differentiation $(1-e)_{s}: \lambda_{s}$ and $\operatorname{ShDiff} f_{s}$. We present the correlations in terms of product and process innovation $\left(\Delta\right.$ Product $_{f}$ and $\Delta$ Process $_{f}$ ) as well as in terms of our alternative measure of innovation: While $\Delta S$ cope $_{f}$ is related to product innovation (firms introduce new varieties and increase product scope), $\Delta$ Flexibility $_{f}$ is related to the ability of the firm to increase the spillover effects among production lines.

Table 3: Correlation between the Degree of Differentiation and the Innovation Variables

\begin{tabular}{lcccc}
\hline$(1-e)_{s}$ & $\Delta$ Product $_{f}$ & $\Delta$ Process $_{f}$ & $\Delta$ Scope $_{f}$ & $\Delta$ Flexibility $_{f}$ \\
\hline$\lambda_{s}$ & $0.249^{* * *}$ & $-0.108^{* *}$ & $0.054^{* * *}$ & $-0.085^{* * *}$ \\
ShDiff $f_{s}$ & $0.048^{* * *}$ & $-0.029^{* *}$ & $0.016^{* *}$ & $-0.031^{*}$ \\
\hline Note: ${ }^{* * *}$ indicates $1 \%$ significance, & ${ }^{* *} 5 \%$ & significance, and & $*$ & $10 \%$ significance. \\
\hline
\end{tabular}

We show that variables related to product innovation $\left(\Delta\right.$ Product $_{f}$ and $\Delta$ Scope $\left._{f}\right)$ are positively correlated with the degree of product differentiation. On the other hand, variables related to process innovation $\left(\Delta\right.$ Process $_{f}$ and $\Delta$ Flexibility $\left._{f}\right)$ are negatively correlated with the degree of product differentiation. Therefore, results in Table 3 are consistent with the predictions from the theoretical model. Moreover, in the section on robustness checks, we show that these correlations are not restricted to the data we use. We combine firm-level data from the World Bank with information on product and process innovation with industrylevel data for Brazilian firms. The correlations between $\lambda_{s}$ and innovation $\left(\Delta\right.$ Product $_{f}$ and $\Delta$ Process $_{f}$ ) confirm our results.

\section{Empirical Strategy}

Our goal in the empirical part of the paper is to test the predictions from the model regarding investment efforts of firms in industries with different scope for product differentiation, following a trade shock. To achieve identification, we estimate the incidence of changes in the innovation investments $\Delta I_{f}$ as a function of the degree of differentiation $(1-e)_{s}$ in the sector $s$ in which the firm operates. To investigate the degree of differentiation $(1-e)_{s}$, we use two different measures: $\lambda_{s}$ according to Khandelwal (2010) and ShDiff following Rauch (1999), as described in the data section. We are interested in the differential effects for industries with different degrees of trade openness, measured by changes in time-varying 
trade-weighted shocks, $\triangle T R E R_{i}$, as follows:

$$
\operatorname{Pr}\left(\Delta I_{f}=1\right)=F\left(\beta_{1} \Delta T R E R_{i}+\beta_{2} \Delta T R E R_{i} *(1-e)_{s}+\alpha_{1} \Delta X_{f}+v_{s}+\varepsilon_{f}\right),
$$

where $f$ indexes the firm, $i$ indexes the industry, $s$ indexes the sector, and $\Delta X_{f}$ is a vector of firm-level time-varying control variables, as described in Table 14 in the Appendix. Initially, we include only changes in firm size, then subsequently we add further control variables. $\varepsilon_{f}$ is a moving-average error term. $v_{s}$ are sector fixed effects, such that we can interpret results within industries in a given sector. ${ }^{18} \Delta I_{f}$ refers to innovation changes conducted by the firm, with $\Delta I_{f}=\Delta$ Process $_{f}$ or $\Delta$ Product $_{f}$. In alternative specifications, $\Delta I_{f}=\Delta$ Scope $_{f}$ or $\Delta$ Flexibility $_{f}$. For simplicity, we omit subscripts for $\Delta . \Delta$ refers to the difference between years $t(2000)$ and $t_{0}(1998), \Delta_{t, t_{0}}$.

In the theoretical model, we state that when market size grows ( $L$ increases), the increase in market size generates incentives for firms to innovate because of scale effects. Empirically, we test changes in market size using a major and unexpected exchange rate shock from 1999 as a source of variation (firms face varying degrees of exposure to foreign markets, and hence, in the access to foreign markets). We exploit this event using industry-specific exchange rate shocks computed over time, $\triangle T R E R_{i}$. Following the predictions from the theoretical model, we expect $\beta_{1}>0$ : An exchange rate devaluation increases incentives for firms to innovate (because of better access to foreign markets), in particular in industries more open to international trade.

On top of that, detailed information on the degree of differentiation $((1-e)$ in the model) and on the type of innovation allows us to evaluate differential effects across industries and sectors. The differential effects are shown by $\beta_{2}$, our main coefficient of interest. $\beta_{2}$ captures the differential impact of the trade shock on firms in differentiated sectors relative to more homogeneous sectors. In response to the shock, scale effects create natural incentives for firms to expand innovation investments. In more differentiated sectors, cannibalization is lower such that firms invest more in product innovation, while in homogeneous sectors spillover effects from innovation are higher such that firms invest more in process innovation. Therefore, $\beta_{2}>0$ in case the dependent variable is $\Delta$ Product $_{f}$, i.e. firms in sectors with a high degree of product differentiation invest more in product innovation, and $\beta_{2}<0$

\footnotetext{
${ }^{18}$ Note that in the theory we have used the words sector and industry interchangeably. In the empirics it is important that $T R E R_{i}$ and $(1-e)_{s}$ have different levels of aggregation, such that the interaction term provides the relevant variation. Therefore, the fact that both variables come from different classification of goods/industries and are aggregated at different levels is an advantage in our approach. Moreover, there is no clear correlation between $(1-e)_{s}$ and between $T R E R_{i}$ or $(1-e)_{s}$ and $\Delta T R E R_{i}$, as we show in Figures 5 and 6 . If the correlation was high, the interaction term could capture non linearities between innovation and the independent variables. Using the continuous measure of differentiation, $\lambda_{s}$, we find no statistically significant correlation between $\lambda_{s}$ and $\triangle T R E R_{i}$.
} 
when the dependent variable is $\Delta$ Process $_{f}$ (firms in more differentiated sectors invest less in process innovation in comparison to firms in more homogeneous sectors).

Our main empirical equation is tested in a first-differences model. Concerning the functional form, we estimate our empirical model using probit and linear probability models, which have different advantages and disadvantages. The linear probability model has the advantage of being easy to estimate and to interpret the coefficients. However, though unbiased, it poses important disadvantages. For instance, the assumption that the error term has unlimited range is not correct, causing problems for hypothesis testing. Moreover, the fitted probabilities may be outside the zero-one boundaries and the marginal impact of $\beta_{2}$ does not exhibit diminishing returns, which would be otherwise expected from the nature of probabilities (the marginal impact should decrease as the independent variable increases). To deal with the concerns with the linear estimation, we estimate the random effects probit model, where $F($.$) is the normal cumulative distribution function. Finally, we also conduct$ robustness checks using seemingly unrelated regressions - SUR, to allow the error terms across equations to be correlated (equations with $\Delta$ Process $_{f}$ or $\Delta$ Product $_{f}$ as dependent variable).

\section{Results}

Tables 4 and 5 present the main empirical results from our paper. In Table 4, we first investigate whether changes in market size lead to more innovation. As predicted by the theoretical model, when the market size grows ( $L$ increases) incentives to innovate increase for all firms and all types of innovation $\left(\beta_{1}>0\right)$. Columns (1) to (4) in Table 4 confirm that $\beta_{1}>0$ for product and process innovation, meaning an increase in the predicted probability of innovation: Following an industry-specific exchange rate devaluation $\left(\triangle T R E R_{i}>0\right)$, firms have higher incentives to invest in product and process innovation. Results are statistically significant using LPM and Probit, shown in the odds and even columns, respectively. Unless otherwise stated, results reported for Probit in the tables include the coefficients, their standard errors, and the value of the likelihood function. To better quantify the results in Table 4, we estimate the marginal effect computed at means of all variables (means are reported in Tables 2 and 13), keeping in mind that probit implies diminishing marginal magnitudes depending on the values of dependent variables. At mean values, the average marginal effect is around 0.27 for product and 0.31 for process innovation, with a p-value of 0.001 in both cases, meaning that the effect is significant.

However, the main interest of the paper refers to the differential effects across sectors and industries. The differential effects using our main measure of differentiation $\lambda_{s}$ are shown 
Table 4: Effect of $\triangle T R E R_{i}$ on Innovation

\begin{tabular}{lcccc}
\hline Dependent variable: & \multicolumn{2}{c}{$\Delta$ Process $_{f}$} & \multicolumn{2}{c}{$\Delta$ Product $_{f}$} \\
& Probit & LPM & Probit & LPM \\
\hline \multirow{2}{*}{$\Delta T R E R_{i}$} & $(1)$ & $(2)$ & $(3)$ & $(4)$ \\
& $0.768^{* * *}$ & $0.296^{* * *}$ & $0.703^{* * *}$ & $0.259^{* * *}$ \\
& $(0.221)$ & $(0.0819)$ & $(0.218)$ & $(0.0778)$ \\
\hline Constant & yes & yes & yes & yes \\
$\Delta$ logNworkers $_{f}$ & yes & yes & yes & yes \\
Sector $s$ fixed effects & yes & yes & yes & yes \\
Log-pseudolikelihood & -1895.239 & & -1776.380 & \\
Pseudo R-squared & 0.010 & & 0.039 & \\
R-squared & & 0.104 & & 0.146 \\
Observations & 3,070 & 3,070 & 3,070 & 3,070 \\
\hline
\end{tabular}

in Table 5. Results confirm the main predictions from our theoretical model. Following an exchange rate devaluation $\left(\triangle T R E R_{i}>0\right)$, firms in industries with a high degree of product differentiation invest more in product innovation relative to other firms $\left(\beta_{2}>0\right.$ when $\Delta I_{f}=\Delta$ Product $_{f}$ ), while firms in industries with a low degree of product differentiation invest more in process innovation relative to other firms $\left(\beta_{2}<0\right.$ when $\Delta I_{f}=\Delta$ Process $\left.f\right)$. Results hold for both estimation strategies (Probit and LPM).

Table 5: Effect of $\triangle T R E R_{i}$ on Innovation for Firms in Different Industries

\begin{tabular}{lcccc}
\hline Dependent variable: & \multicolumn{2}{c}{$\Delta$ Process $_{f}$} & \multicolumn{2}{c}{$\Delta$ Product $_{f}$} \\
& Probit & LPM & Probit & LPM \\
\hline \multirow{3}{*}{$\lambda_{s} * \Delta T R R_{i}$} & $(1)$ & $(2)$ & $(3)$ & $(4)$ \\
& $-0.316^{* * *}$ & $-0.124^{* * *}$ & $0.278^{* * *}$ & $0.106^{* * *}$ \\
$\Delta T R E R_{i}$ & $(0.0840)$ & $(0.0331)$ & $(0.0412)$ & $(0.0154)$ \\
& $0.868^{* * *}$ & $0.329^{* * *}$ & $0.553^{* *}$ & $0.199^{* *}$ \\
& $(0.224)$ & $(0.0810)$ & $(0.218)$ & $(0.0773)$ \\
\hline Constant & yes & yes & yes & yes \\
$\Delta$ logNworker $s_{f}$ & yes & yes & yes & yes \\
Sector $s$ fixed effects & yes & yes & yes & yes \\
Log-pseudolikelihood & -1892.544 & & -1775.112 & \\
Pseudo R-squared & 0.011 & & 0.040 & \\
R-squared & & 0.104 & & 0.147 \\
Observations & 3,070 & 3,070 & 3,070 & 3,070 \\
\hline
\end{tabular}

For probit, results in Table 5 columns (1) and (3) report the coefficients. To evaluate magnitudes, we compute the difference in probabilities depending on different values of $\triangle T R E R_{i}$ and $\lambda_{s}$, since the value of the interaction effect changes upon the value of the continuous predictor variable. At mean values of all variables, the marginal effect of $\triangle T R E R_{i}$ is 0.21 for product and 0.34 for process innovation. For the interaction term, the marginal 
effect is 0.10 for product and -0.12 for process innovation, evaluated at mean values. Marginal effects are in all cases statistically significant at the one percent level. Therefore, we confirm that firms in more homogeneous sectors are significantly more likely to do process innovation following the shock, whereas firms in more differentiated sectors are more likely to do product innovation. Columns (2) and (4) report results for the LPM. If we evaluate mean values of $\triangle T R E R_{i}$ and $\lambda_{s}$, a decrease in $\lambda_{s}$ by two standard deviations leads to an increase in the probability to do process innovation by roughly 2 percent, with this value being higher for firms in sectors with higher initial $\lambda_{s}$. For product innovation, an increase in $\lambda_{s}$ by two standard deviations leads to an increase in product innovation by roughly 4 percent.

One may argue that the measures of product and process innovation used in Table 5 are disconnected from the theoretical model. Changes in process innovation $\left(\Delta\right.$ Process $\left._{f}\right)$ may reflect an innovation not directly related to internalization of spillovers. We address this concern using an alternative measure of innovation related to spillover effects, $\Delta$ Flexibility $_{f}$. Results presented in Table 6 reveal that estimations are robust to this alternative measure of process innovation.

A similar concern refers to the mechanism related to product innovation $\left(\Delta\right.$ Product $\left._{f}\right)$. Investments in product innovation may reflect changes in an already existent product rather than the creation of an additional variety. We address this concern using an alternative measure of innovation related to changes in product scope, $\Delta S c o p e_{f}$. Results shown in Table 6 are consistent with the baseline estimations from Table 5.

Table 6: Effect of $\triangle T R E R_{i}$ on Product Scope and Production Flexibility

\begin{tabular}{lcccc}
\hline Dependent variable: & \multicolumn{2}{c}{$\Delta$ Scope $_{f}$} & \multicolumn{2}{c}{$\Delta$ Flexibility $_{f}$} \\
& Probit & LPM & Probit & \multicolumn{1}{c}{ LPM } \\
\hline \multirow{4}{*}{$\lambda_{s} * \Delta R E R_{i}$} & $(1)$ & $(2)$ & $(3)$ & $(4)$ \\
& $0.195^{* * *}$ & $0.0497^{* * *}$ & $-0.164^{* * *}$ & $-0.0614^{* * *}$ \\
$\Delta T R E R_{i}$ & $(0.0620)$ & $(0.0123)$ & $(0.0527)$ & $(0.0196)$ \\
& $0.594^{* * *}$ & $0.303^{* * *}$ & $0.745^{* *}$ & $0.272^{* *}$ \\
& $(0.194)$ & $(0.0548)$ & $(0.314)$ & $(0.114)$ \\
\hline Constant & yes & yes & yes & yes \\
$\Delta$ logNworkers $f$ & yes & yes & yes & yes \\
Sector $s$ fixed effects & yes & yes & yes & yes \\
Log-pseudolikelihood & -567.767 & & -1255.563 & \\
Pseudo R-squared & 0.050 & & 0.019 & \\
R-squared & & 0.094 & & 0.069 \\
Observations & 3,070 & 3,070 & 1,971 & 1,971 \\
\hline
\end{tabular}




\section{Robustness Checks}

Rauch (1999) Measure of Product Differentiation We use ShDif $f_{s}$ as an alternative measure to $\lambda_{s}$ and replicate the interaction effects from Table 5. Results are shown in Table 7 columns (1) and (3). While smaller in magnitudes, the effect confirms the expected coefficients for $\beta_{1}$ and $\beta_{2}$.

Degree of Differentiation: Firm-level Measure As a further alternative measure to $\lambda_{s}$, we build a firm-level ladder $\lambda_{f}$ starting from the 10-digit product classification, made available by Khandelwal (2010). This measure allows us to exploit the degree of differentiation at the firm-level, since we have information on all 6-digit products exported by Brazilian firms. Thus, we combine these data and create the mean ladder at the firm level $\lambda_{f}$ corresponding to the average ladder of the products exported by the firm, as follows: $\lambda_{f}=\frac{\sum_{f p} \lambda_{f p}}{N}$, where $N$ is the initial number of products exported by the firm in the year 1998. $\lambda_{f}$ provides higher variation in comparison to $\lambda_{s}$ : While $\lambda_{s}$ has a standard deviation of $0.21, \lambda_{f}$ has a standard deviation of 0.6. The means are very close, 1.73 for $\lambda_{s}$ and 1.75 for $\lambda_{f}$.

Results using $\lambda_{f}$ are shown in Table 7 in columns (2) and (4) and are consistent with our predictions. However, data at the firm and product-level on the degree of differentiation are not essential to our argument and may be subject to endogeneity once we exploit time variation. ${ }^{19}$ Therefore, our preferred empirical specification uses information at the sector and industry-level.

Asymmetries across Firms One important concern with our baseline estimations refers to firms that do both types of innovation. Many firms invest simultaneously in product and process innovation following the exchange rate shock. Therefore, we evaluate asymmetries across different groups of firms. In particular, we evaluate the effects for firms that do only one type of innovation.

While the baseline estimations using $\Delta I_{f}=\Delta$ Process $_{f}$ or $\Delta$ Product $_{f}$ consider all firms that reported process and product innovation efforts, respectively, here we evaluate the effect for firms that reported only one or the other type of innovation. $\Delta$ Process_only $=1$ for firms that reported only process innovation, zero otherwise. Similar for product innovation $(\Delta \text { Product_only })_{f}$. Estimations with $\Delta$ Process_only $y_{f}$ and $\Delta$ Product_only $y_{f}$ as dependent variables reveal that results are in general larger in magnitudes for firms reporting only one type of innovation (results in columns (1) to (4) from Table 8). We interpret this result

\footnotetext{
${ }^{19}$ For instance, if firms invest in product innovation they may increase the degree of differentiation of the products they offer over time. However, at the industry level this effect is less severe and does not affect our main predictions.
} 
as follows: Firms in the extremes of the distribution of product differentiation have lower incentives to invest in both types of innovation. Imagine firms producing bricks versus firms producing luxury watches (a highly homogeneous and a highly differentiated product, respectively). While firms in the middle of the distribution will have higher incentives to allocate part of their resources to each type of innovation, firms in the extremes of the distribution such as watches and bricks have higher returns to innovation when they allocate resources in only one type of innovation.

Results Adding further Firm-level Control Variables We add several firm-level variables to the main specification and show that results remain stable. The stability of results suggest that omitted variables might not be a major concern.

The variables we add relate to firm initial characteristics in year $1998, X_{f, t=0}$. Firms that are larger, foreign-owned and with a more skilled labor force are in general more innovative. Therefore, we investigate the stability of our results when adding the following firm initial conditions: Number of workers as a proxy for firm size $\left(\log N\right.$ worker $\left.s_{f, t=0}\right)$, foreign ownership dummy $\left(F D I_{f, t=0}\right)$, share of workers with tertiary education as a proxy for worker skills $\left(\right.$ Skill $\left._{f, t=0}\right)$, the number of products exported by the firm $\left(\log\right.$ Nproduct $\left._{f, t=0}\right)$, and the number of destinations of exports ( $\log N$ destination $\left.s_{f, t=0}\right)$. The description of variables and the associated means and standard deviations are reported in Table 13.

Results are shown in Table 9. As expected, all coefficients are positive and statistically significant, meaning that larger, foreign-owned, and firms with a higher share of skilled workers do more innovation. Crucially, as shown in Table 9, the interaction term shown by $\beta_{2}$ remains significant and stable through all specifications. In results available upon request, we also add the change in these same variables over the period. While the point estimates are in many cases not statistically significant (since the period is relatively short), the signs are informative and consistent with the literature.

Results Using SUR We check whether our results remain robust to further estimations strategies. In the baseline results, we have estimated LPM and Probit separately for product and process innovation. To allow the error terms of the two equations to be correlated, we estimate a seemingly unrelated regressions model (SUR). Results reported in Table 11 reveal that coefficients are the same in comparison to the LPM (as expected), but the error terms are slightly higher when we allow them to be correlated. Results remain significant in all cases. 
Exchange Rate Shock: Alternative Measures We conduct several robustness checks to evaluate the stability of our results with respect to alternative measures of $\triangle T R E R_{i}$.

First, we look at lagged exports. One concern with the estimations using $\triangle T R E R_{i}$ is endogeneity between trade and the exchange rate. We avoid this concern using lagged import shares $\left(\frac{M_{i c, t-1}}{\sum_{c} M_{i c, t-1}}\right)$ and lagged export shares $\left(\frac{X_{i c, t-1}}{\sum_{c} X_{i c, t-1}}\right)$. Columns (1) and (2) in Table 10 show that results remain robust when we use lagged exports.

Second, instead of using industry-specific import shares $\left(\frac{M_{i c t}}{\sum_{c} M_{i c t}}\right)$ and export shares $\left(\frac{X_{i c t}}{\sum_{c} X_{i c t}}\right)$ to construct $T R E R_{i t}$, we construct an alternative measure using only export shares, as follows: $X T R E R_{i t}=\sum_{c}\left(\frac{X_{i c t}}{\sum_{c} X_{i c t}} * r e r_{c t}\right)$. The advantage of using export shares separately is to separate export shocks from import shocks. One concern with the estimations using $\triangle T R E R_{i}$ is that an exchange rate shock may mean increases in market size for some industries but not for others (depending on input intensity, among others). Using the exchange rate shock separately for imports and exports, we exploit whether factors unrelated to market size are driving our results. Results are reported in Table 10 in columns (3) and (4). Also in this case our main hypotheses remain robust.

Results Using Innovation Data from the World Bank One could argue that the correlation we find between $\lambda_{s}$ and product/process innovation is specific to our data. To overcome this concern, we use firm-level innovation data from the World Bank (Business Environment and Enterprise Performance Survey (BEEPS)) for Brazil in the year 2003. The innovation survey contains information on investments in product and process innovation. We build the following variables for product and process innovation. Product_ $W B_{f}=1$ if the firm answered yes to the following question: "Initiative undertaken in last 3 years: new product line?", otherwise Product_W $B_{f}=0$. Process_W $B_{f}=1$ if the firm answered yes to the following question: "Initiative undertaken in last 3 years: new technology?", otherwise Process_W $B_{f}=0$. We combine the World Bank data with the Khandelwal (2010) measure of differentiation using the Brazilian industry classification available at the World Bank.

The World Bank data do not allow us to fully test our model. However, we can calculate the correlation between $\lambda_{s}$ and innovation (Product_W $B_{f}$ and Process_ $W B_{f}$ ) and compare with the correlations we find using the PINTEC (2000) data. Results shown in Table 12 confirm the correlations presented in Table 3 using the PINTEC (2000) firm-level data. 


\section{Conclusion}

This paper is inspired by growing evidence on the importance of within-firm adjustments in explaining gains from trade. A recent strand of the literature in international trade emphasizes that innovating firms account for a large fraction of the productivity and variety gains within sectors. In this paper, we provide a new model of MPFs, allowing for endogenous investments in both product and process innovation. Following an increase in the market size, we show how firms increase investments of both types. The focus of this model, however, is on an industry-specific trade-off between the two types of innovation, which arises through demand and cost linkages specific to MPFs. Both linkages are related to the degree of product differentiation in a sector, leading to heterogenous returns to the two types of innovation across industries.

Our model shows that firms in sectors with a high scope for differentiation invest more in product and less in process innovation. In a highly differentiated industry, returns to product innovation are high as cannibalization effects within the firm are low. Returns to process innovation, however, are lower in a differentiated sector as more differentiated products are associated with more dissimilar production processes. Therefore, in more differentiated sectors, process innovation is highly product-specific and is not applicable to the whole range of products within the firm. Obviously, for firms in homogeneous industries, the mechanism works exactly the other way round.

Our model provides novel predictions, which are tested using Brazilian firm-level data. We combine detailed information on the two types of innovation featured in our theory with an unexpected exchange rate devaluation as an exogenous source of variation to test the effect of market size on innovation. For Brazilian exporters, the currency devaluation

improves foreign market access without losing domestic market shares. We find that, given the larger market, firms reoptimize their investments and increase spending in both types of innovation. Moreover, we are able to evaluate differential effects across industries. Using several measures for the degree of product differentiation in a sector, we show that firms in differentiated sectors focus on product innovation while firms in more homogeneous sectors innovate more in better processes. 


\section{References}

[1] Almeida, R. and Poole, J.P. (2013) "Trade and Labor Reallocation with Heterogeneous Enforcement of Labor Regulations". IZA Discussion Papers 7358.

[2] Arkolakis, C. and Muendler, M.A. (2010) "The Extensive Margin of Exporting Products: A Firm-level Analysis". NBER Working Papers, 16641.

[3] Aw, B. Y., Roberts M. J. and Xu D. Y. (2011) "R\&D Investment, Exporting, and Productivity Dynamics". American Economic Review, 101(4): 1312-44.

[4] Bernard, A., Jensen, B., Redding, S. and Schott P. (2007) "Firms in International Trade". Journal of Economic Perspectives, 21, 105-130.

[5] Bernard, A., Redding, S. and Schott P. (2010) "Multiple-Product Firms and Product Switching". American Economic Review, 100(1), 70-97.

[6] Broda, C. and Weinstein, D. E. (2010) "Product Creation and Destruction: Evidence and Price Implications". American Economic Review, 100(3), 691-723.

[7] Bustos, P. (2011) "Trade Liberalization, Exports, and Technology Upgrading: Evidence on the Impact of MERCOSUR on Argentinian Firms". American Economic Review, 101, 304-340.

[8] Dhingra, S. (2013) "Trading Away Wide Brands for Cheap Brands". American Economic Review, 103(6), 2554-84.

[9] Doraszelski, U. and Jaumandreu, J. (2013) "Estimating Endogenous Productivity". Review of Economic Studies, 80, 1338-1383.

[10] Eckel, C., Iacovone, L., Javorcik, B. and Neary, J.P. (2011) "Multi-Product Firms at Home and Away: Cost- versus Quality-based Competence". CEPR Discussion Papers 8186.

[11] Eckel, C. and Neary, P.J. (2010) "Multi-product Firms and Flexible Manufacturing in the Global Economy". Review of Economic Studies, 77 , 188-217.

[12] Feenstra, R. C., Lipsey, R. E., Deng, H., Ma, A. C. and Mo, H. (2005): "World Trade Flows: 1962-2000". NBER Working Paper No. 11040.

[13] Feenstra, R. and Ma H. (2008) "Optimal Choice of Product Scope for Multiproduct Firms under Monopolistic Competition", In: Helpman E., Marin D., and Verdier T. 
(Eds.), The Organization of Firms in a Global Economy. Cambridge, MA and London, England: Harvard University Press, 173-199.

[14] Goldberg, L. S. (2004) "Industry-specific Exchange Rates for the United States". Economic Policy Review, Federal Reserve Bank of New York, 1-16.

[15] Grossman, G. M. and Helpman E. (1991) "Quality Ladders in the Theory of Growth". Review of Economic Studies, 58 (1): 43-61.

[16] Khandelwal, A. (2010) "The Long and Short (of) Quality Ladders". Review of Economic Studies, 77, 1450-1476.

[17] Lileeva, A. and Trefler, D. (2010) "Improves Access to Foreign Markets Raises PlantLevel Productivity...for some Plants". The Quarterly Journal of Economics, 125 (3), 1051-1099.

[18] Mayer, T., Melitz M. J. and Ottaviano G. I. P. (2014) "Market Size, Competition, and the Product Mix of Exporters". American Economic Review, 104(2): 495-536.

[19] Melitz, M. J. (2003) "The Impact of Trade on Intra-Industry Reallocations and Aggregate Industry Productivity". Econometrica, 71(6), 1695-1725.

[20] Melitz, M. and Ottaviano, G. (2008) "Market Size, Trade and Productivity". Review of Economic Studies, 75, 296-316.

[21] PINTEC (2000) "Pesquisa Industrial de Inovação Tecnológica". Instituto Brasileiro de Geografia e Estatística RJ/RJ.

[22] Qiu L. D. and Zhou W. (2013) "Multiproduct Firms and Scope Adjustment in Globalization". Journal of International Economics, 91, 142-153.

[23] Rauch, J. E., (1999) "Networks versus Markets in International Trade". Journal of International Economics 48, 7-35.

[24] Verhoogen, E. A. (2008) "Trade, Quality Upgrading, and Wage Inequality in the Mexican Manufacturing Sector". The Quarterly Journal of Economics, 123 (2), 489-530.

[25] Yeaple, S. R. (2005) "A Simple Model of Firm Heterogeneity, International Trade, and Wages". Journal of International Economics, 65 (1), 1-20. 


\section{Appendix}

\subsection{Derivation of Eq. (31)}

Combining Eqs. (19) at $i=\delta$ and (24) yields:

$$
b^{\prime} r_{k}(1-e) x(\delta)^{2}=((1-\theta(e)) x(\delta)+\theta(e) X)((1-\theta(e)) x(\delta)-\theta(e) X)+r_{\delta} r_{k} .
$$

The expression on the right-hand side $((1-\theta(e)) x(\delta)+\theta(e) X)((1-\theta(e)) x(\delta)-\theta(e) X)$ can be rewritten as: $((1-\theta(e)) x(\delta))^{2}-(\theta(e) X)^{2}$. Solving for $x(\delta)$ yields the expression in Eq. (31).

\subsection{Market Size Effect - Proposition 1}

We totally differentiate the two equilibrium conditions for scale and scope in Eqs. (28) and (32) and write the results in matrix notation.

$$
\begin{gathered}
{\left[\begin{array}{cc}
r_{k} \delta\left(a-c-c_{1} \frac{\delta}{2}\right) & -2\left(b^{\prime} r_{k}(1-e)-\left(1-e^{\kappa}\right)^{2}\right) x(\delta) \delta \\
\left(\left(e b^{\prime} r_{k}-e^{\kappa}\left(2\left(1-e^{\kappa}\right)+e^{\kappa} \delta\right)\right)-\frac{e^{2 \kappa} X}{x(\delta)}\right) 2 X & \left(r_{k} c_{1}-2 e^{2 \kappa} X\right) \delta
\end{array}\right]\left[\begin{array}{c}
d \ln X \\
d \ln \delta
\end{array}\right]} \\
=-\left[\begin{array}{c}
2 X(1-e+e \delta) \\
((1-e) x(\delta)+2 e X)
\end{array}\right] b^{\prime} r_{k} d \ln b^{\prime}+\left[\begin{array}{c}
\delta \\
1
\end{array}\right] r_{k} a d \ln a
\end{gathered}
$$

To derive this matrix, we use information from Eqs. (28), (30), and (31). The determinant $\Delta$ of the system is always positive. The fact that $\Delta>0$ ensures a unique and stable equilibrium. Condition 1 stated in Eq. (23) ensures that $\left(\left(e b^{\prime} r_{k}-e^{\kappa}\left(2\left(1-e^{\kappa}\right)+e^{\kappa} \delta\right)\right)-\frac{e^{2 \kappa} X}{x(\delta)}\right)>0$. To proof the latter result, we compute an alternative expression for total firm scale by integrating over per variety scale in Eq. (25):

$$
X=\frac{c_{1}\left(\frac{\delta^{2}}{2}\right)}{2\left(b^{\prime}(1-e)-\frac{\left(1-e^{\kappa}\right)^{2}}{r_{k}}\right)}+\delta x(\delta)
$$

Combining the latter expression with the condition in Eq. (23) yields:

$$
e b^{\prime} r_{k} x(\delta)>2 e^{\kappa}\left(1-e^{\kappa}\right) x(\delta)+e^{2 \kappa} \delta x(\delta)+e^{2 \kappa} X+e^{2 \kappa} \frac{c_{1}\left(\frac{\delta^{2}}{2}\right)}{2\left(b^{\prime}(1-e)-\frac{\left(1-e^{\kappa}\right)^{2}}{r_{k}}\right)}
$$

and ensures that $\Delta>0$. 
Effect on Firm Scale $X$ : The effect of an increase (decrease) in $L\left(b^{\prime}\right)$ on total firm size can be expressed as follows:

$$
\frac{d \ln X}{d \ln b^{\prime}}=\frac{1}{\Delta}\left|\begin{array}{cc}
-2 X(1-e+e \delta) b^{\prime} r_{k} & -2\left(b^{\prime} r_{k}(1-e)-\left(1-e^{\kappa}\right)^{2}\right) x(\delta) \delta \\
-((1-e) x(\delta)+2 e X) b^{\prime} r_{k} & \left(r_{k} c_{1}-2 e^{2 \kappa} X\right) \delta
\end{array}\right|<0
$$

As the sign of the matrix is clearly negative, an increase in the market size increases total firm size $X$. An increase in the demand intercept $a$, leads to the same qualitative result:

$$
\frac{d \ln X}{d \ln a}=\frac{1}{\Delta}\left|\begin{array}{cc}
\delta a r_{k} & -2\left(b^{\prime} r_{k}(1-e)-\left(1-e^{\kappa}\right)^{2}\right) x(\delta) \delta \\
a r_{k} & \left(r_{k} c_{1}-2 e^{2 \kappa} X\right) \delta
\end{array}\right|>0
$$

Effect on Optimal Scope $\delta$ : The effect of an increase (decrease) in $L\left(b^{\prime}\right)$ on optimal scope can be expressed as follows:

$$
\frac{d \ln \delta}{d \ln b^{\prime}}=\frac{1}{\Delta}\left|\begin{array}{cc}
r_{k} \delta\left(a-c-c_{1} \frac{\delta}{2}\right) & -2 X(1-e+e \delta) b^{\prime} r_{k} \\
\left(\left(e b^{\prime} r_{k}-e^{\kappa}\left(2\left(1-e^{\kappa}\right)+e^{\kappa} \delta\right)\right)-\frac{e^{2 \kappa} X}{x(\delta)}\right) 2 X & -((1-e) x(\delta)+2 e X) b^{\prime} r_{k}
\end{array}\right|<0
$$

Note that the sign of the matrix $\Delta_{b^{\prime}}$ can be defined unambiguously as:

$$
\Delta_{b^{\prime}}=-\left\{\begin{array}{c}
\left(b^{\prime} r_{k}(1-e+e \delta)-\left(1-e^{\kappa}+e^{\kappa} \delta\right)^{2}\right)((1-e) x(\delta)) \\
+2 X\left(\left(2 e^{\kappa}\left(1-e^{\kappa}\right)-e\left(1-e^{2 \kappa}\right)+(1-e) e^{2 \kappa} \delta\right)+(1-e+e \delta) \frac{e^{2 \kappa} X}{x(\delta)}\right)
\end{array}\right\}<0 .
$$

Therefore, an increase in the market size clearly induces the firm to increase its optimal product range. Again, we derive the same qualitative result for an increase in $a$ :

$$
\frac{d \ln \delta}{d \ln a}=\frac{1}{\Delta}\left|\begin{array}{cc}
r_{k} \delta\left(a-c-c_{1} \frac{\delta}{2}\right) & \delta a r_{k} \\
\left(\left(e b^{\prime} r_{k}-e^{\kappa}\left(2\left(1-e^{\kappa}\right)+e^{\kappa} \delta\right)\right)-\frac{e^{2 \kappa} X}{x(\delta)}\right) 2 X & a r_{k}
\end{array}\right|>0
$$

The sign of the matrix $\Delta_{a}$ is clearly positive as:

$$
\Delta_{a}=\left(b^{\prime} r_{k}(1-e)-1+e^{\kappa}\left(2-e^{\kappa}\right)+\frac{e^{2 \kappa} \delta X}{x(\delta)}\right) 2 X a r_{k}>0 .
$$

Effect on Process Innovation $K$ : After having determined the market size effects on scale $X$ and scope $\delta$, identifying the market size effect on process innovation $K$ is trivial. Totally differentiating Eq. (29) yields the following results:

$$
r_{k} K \frac{d \ln K}{d \ln b^{\prime}}=\left(1-e^{\kappa}+e^{\kappa} \delta\right) X \frac{d \ln X}{d \ln b^{\prime}}+e^{\kappa} \delta X \frac{d \ln \delta}{d \ln b^{\prime}}<0,
$$


and

$$
r_{k} K \frac{d \ln K}{d \ln a}=\left(1-e^{\kappa}+e^{\kappa} \delta\right) X \frac{d \ln X}{d \ln a}+e^{\kappa} \delta X \frac{d \ln \delta}{d \ln a}>0 .
$$

The result clearly shows that an increase in the market size $L$ or the demand intercept $a$ will induce the firm to invest more in better processes.

\subsection{Effect of Degree of Product Differentiation - Proposition 2}

Differentiating Eq. (32) with respect to $e$ and substituting information from Eq. (31), gives:

$$
\frac{\partial \ln \delta}{\partial \ln e}=-\frac{\left((2 X-x(\delta))\left(e b^{\prime} r_{k}-2 \kappa e^{\kappa}\left(1-e^{\kappa}\right)\right) x(\delta)-2 \kappa e^{2 \kappa} X(2(\delta-1) x(\delta)+X)\right)}{\left(c_{1} r_{k}-2 e^{2 \kappa} X\right) x(\delta) \delta}
$$

For very strong (weak) spillovers, i.e. low (high) values of $\kappa$ holds: $\lim _{\kappa \rightarrow 0} \frac{\partial \ln \delta}{\partial \ln e}<0$ and $\lim _{\kappa \rightarrow \infty} \frac{\partial \ln \delta}{\partial \ln e}<0$. For intermediate values of spillovers, the sign of the derivative in Eq. (50) depends on the perceived costs of process innovation $b^{\prime} r_{k}$ (see discussion of Condition 1). If costs for process innovation are sufficiently high, then: $\frac{\partial \ln \delta}{\partial \ln e}<0$. Furthermore, we can take the derivative of Eq. (32) with respect to $e$ and evaluate it at $e=0$ :

$$
\left.\frac{\partial \delta}{\partial e}\right|_{e=0}=-\frac{b^{\prime}(2 X-x(\delta))}{c_{1}}<0
$$

The latter implies that even in the case of perfectly differentiated products, a small increase in $e$ will reduce the optimal product range $\delta$. 


\subsection{Robustness Checks}

Table 7: Effect of $\triangle T R E R_{i}$ on Innovation Using Alternative Measures of Differentiation

\begin{tabular}{lcccc}
\hline Dependent variable: & \multicolumn{2}{c}{$\Delta$ Process $_{f}$} & \multicolumn{2}{c}{$\Delta$ Product $_{f}$} \\
& ShDiff & $\lambda_{f}$ & ShDiff $_{s}$ & $\lambda_{f}$ \\
& LPM & LPM & LPM & LPM \\
\hline \multirow{3}{*}{ ShDiff $f_{s} * \Delta R E R_{i}$} & $-0.0649^{* * *}$ & $(2)$ & $(3)$ & $(4)$ \\
& $(0.0180)$ & & $0.0857^{* * *}$ & \\
$\lambda_{f} * \Delta T R E R_{i}$ & & $-0.140^{* * *}$ & & $0.129^{* * *}$ \\
& & $(0.0459)$ & & $(0.0127)$ \\
$\Delta T R E R_{i}$ & $0.301^{* * *}$ & $0.414^{* * *}$ & $0.252^{* * *}$ & $0.259^{* * *}$ \\
& $(0.0808)$ & $(0.158)$ & $(0.0768)$ & $(0.0778)$ \\
\hline Constant & yes & yes & yes & yes \\
$\Delta$ logNworkers $s_{f}$ & yes & yes & yes & yes \\
Sector $s$ fixed effects & yes & yes & yes & yes \\
R-squared & 0.104 & 0.104 & 0.146 & 0.147 \\
Observations & 3,070 & 3,070 & 3,070 & 3,070 \\
\hline
\end{tabular}

Table 8: Effect of $\triangle T R E R_{i}$ for Firms that Do only One Type of Innovation

\begin{tabular}{|c|c|c|c|c|}
\hline \multirow[t]{2}{*}{ Dependent variable: } & \multicolumn{2}{|c|}{$\begin{array}{l}\text { Only process } \\
\text { innovation }\end{array}$} & \multicolumn{2}{|c|}{$\begin{array}{l}\text { Only product } \\
\text { innovation }\end{array}$} \\
\hline & Probit & LPM & Probit & LPM \\
\hline & $(1)$ & $(2)$ & $(3)$ & $(4)$ \\
\hline$\lambda_{s} * \Delta T R E R_{i}$ & $\begin{array}{c}-0.657^{* * *} \\
(0.154)\end{array}$ & $\begin{array}{c}-0.179^{* * *} \\
(0.0421)\end{array}$ & $\begin{array}{c}0.509^{* * *} \\
(0.123)\end{array}$ & $\begin{array}{c}0.102^{* * *} \\
(0.0245)\end{array}$ \\
\hline$\Delta T R E R_{i}$ & $\begin{array}{c}1.895^{* * *} \\
(0.543)\end{array}$ & $\begin{array}{c}0.512^{* * *} \\
(0.153)\end{array}$ & $\begin{array}{c}0.942^{* * * *} \\
(0.279)\end{array}$ & $\begin{array}{c}0.201^{* * *} * \\
(0.0720)\end{array}$ \\
\hline Constant & yes & yes & yes & yes \\
\hline$\Delta \log N$ workers $f$ & yes & yes & yes & yes \\
\hline Sector $s$ fixed effects & yes & yes & yes & yes \\
\hline Log-pseudolikelihood & -1343.687 & & -1051.554 & \\
\hline Pseudo R-squared & 0.084 & & 0.086 & \\
\hline R-squared & & 0.109 & & 0.121 \\
\hline Observations & 3,070 & 3,070 & 3,070 & 3,070 \\
\hline
\end{tabular}


Table 9: Effect of $\triangle T R E R_{i}$ on Innovation - Results Adding further Control Variables

\begin{tabular}{|c|c|c|c|c|c|c|c|c|c|c|}
\hline \multirow[t]{2}{*}{ Dependent variable: } & \multicolumn{5}{|c|}{$\Delta$ Process $_{f}$} & \multicolumn{5}{|c|}{$\Delta$ Product $_{f}$} \\
\hline & $(1)$ & $(2)$ & $(3)$ & $(4)$ & $(5)$ & $(6)$ & $(7)$ & $(8)$ & $(9)$ & $(10)$ \\
\hline$\Delta T R E R_{i}$ & $0.356^{* * *}$ & $0.366^{* * *}$ & $0.315^{* * *}$ & $0.334^{* * *}$ & $0.358 * * *$ & $0.220 * * *$ & $0.238^{* * *}$ & $0.169^{* *}$ & $0.195^{* * *}$ & $0.212^{* * *}$ \\
\hline & $(0.0783)$ & $(0.0795)$ & $(0.0775)$ & $(0.0801)$ & $(0.0803)$ & $(0.0764)$ & $(0.0715)$ & $(0.0742)$ & $(0.0739)$ & $(0.0785)$ \\
\hline$\lambda_{s} * \Delta T R E R_{i}$ & $-0.120^{* * *}$ & $-0.181^{* * *}$ & $-0.146^{* * *}$ & $-0.159^{* * *}$ & $-0.121^{* * *}$ & $0.106^{* * *}$ & $0.0918^{* * *}$ & $0.108^{* * *}$ & $0.0981^{* * *}$ & $0.109^{* * *}$ \\
\hline & $(0.0321)$ & $(0.0344)$ & $(0.0322)$ & $(0.0335)$ & $(0.0320)$ & $(0.0153)$ & $(0.0149)$ & $(0.0149)$ & $(0.0151)$ & $(0.0153)$ \\
\hline $\log N$ destinations $_{f, t}=0$ & $0.0970 * * *$ & & & & & $0.0808^{* * *}$ & & & & \\
\hline & $(0.00795)$ & & & & & $(0.00795)$ & & & & \\
\hline Skills $_{f, t=0}$ & & $0.391^{* * *}$ & & & & & $0.890^{* * *}$ & & & \\
\hline & & $(0.0718)$ & & & & & $(0.0695)$ & & & \\
\hline $\log N$ products $f, t=0$ & & & $0.0880^{* * *}$ & & & & & $0.118^{* * *}$ & & \\
\hline & & & $(0.00728)$ & & & & & $(0.00680)$ & & \\
\hline$F D I_{f, t=0}$ & & & & $0.161^{* * *}$ & & & & & $0.257^{* * *}$ & \\
\hline & & & & $(0.0241)$ & & & & & $(0.0234)$ & \\
\hline $\log N$ workers $s_{f, t=0}$ & & & & & $0.0859 * * *$ & & & & & $0.0785^{* * *}$ \\
\hline & & & & & $(0.00703)$ & & & & & $(0.00677)$ \\
\hline Constant & yes & yes & yes & yes & yes & yes & yes & yes & yes & yes \\
\hline$\Delta \log N$ workers $f$ & yes & yes & yes & yes & yes & yes & yes & yes & yes & yes \\
\hline Sector $s$ fixed effects & yes & yes & yes & yes & yes & yes & yes & yes & yes & yes \\
\hline R-squared & 0.142 & 0.107 & 0.132 & 0.112 & 0.166 & 0.177 & 0.168 & 0.195 & 0.163 & 0.191 \\
\hline Observations & 3,070 & 3,070 & 3,070 & 3,070 & 3,070 & 3,070 & 3,070 & 3,070 & 3,070 & 3,070 \\
\hline
\end{tabular}


Table 10: Effect on Innovation Using Alternative Measures of $T R E R_{i t}$

\begin{tabular}{lcccc}
\hline & & \multicolumn{3}{c}{ LPM } \\
Dependent variable: & $\Delta$ Process $_{f}$ & $\Delta$ Product $_{f}$ & $\Delta$ Process $_{f}$ & $\Delta$ Product $_{f}$ \\
\hline \multirow{2}{*}{$\lambda_{s} * \Delta T R E R_{i, t-1}$} & $(1)$ & $(2)$ & $(3)$ & $(4)$ \\
& $-0.118^{* * *}$ & $0.0903^{* * *}$ & & \\
$\Delta T R E R_{i, t-1}$ & $(0.0438)$ & $(0.0147)$ & & \\
& $0.295^{* * *}$ & $0.194^{* *}$ & & \\
$\lambda_{s} * \Delta X T R E R_{i}$ & $(0.0829)$ & $(0.0901)$ & & \\
& & & $-0.276^{* * *}$ & $0.163^{* * *}$ \\
$\Delta X T R E R_{i}$ & & & $(0.0425)$ & $(0.0386)$ \\
& & & $0.359^{* * *}$ & $0.414^{* * *}$ \\
& & & $(0.0794)$ & $(0.158)$ \\
\hline Constant & yes & yes & yes & yes \\
$\Delta \log N w o r k e r s_{f}$ & yes & yes & yes & yes \\
Sector $s$ fixed effects & yes & yes & yes & yes \\
R-squared & 0.105 & 0.147 & 0.104 & 0.149 \\
Observations & 3,041 & 3,041 & 3,070 & 3,070 \\
\hline
\end{tabular}

Table 11: Effect of $\triangle T R E R_{i}$ on Innovation Using SUR

\begin{tabular}{lcccc}
\hline & \multicolumn{2}{c}{ SUR 1} & \multicolumn{2}{c}{ SUR 2} \\
Dependent variable: & $\Delta$ Process $_{f}$ & $\Delta$ Product $_{f}$ & $\Delta$ Process $_{f}$ & $\Delta$ Product $_{f}$ \\
\hline \multirow{2}{*}{$\lambda_{s} * \Delta T R E R_{i}$} & $(1)$ & $(2)$ & $(3)$ & $(4)$ \\
& & & $-0.124^{* * *}$ & $0.106^{* * *}$ \\
$\Delta T R E R_{i}$ & & & $(0.0334)$ & $(0.0155)$ \\
& $0.296^{* * *}$ & $0.259^{* * *}$ & $0.329^{* * *}$ & $0.199^{* *}$ \\
& $(0.0907)$ & $(0.0896)$ & $(0.0920)$ & $(0.0899)$ \\
\hline Constant & yes & yes & yes & yes \\
$\Delta$ logNworker $s_{f}$ & yes & yes & yes & yes \\
Sector $s$ fixed effects & yes & yes & yes & yes \\
R-squared & 0.104 & 0.146 & 0.107 & 0.149 \\
Observations & 3,070 & 3,070 & 3,070 & 3,070 \\
\hline
\end{tabular}

Table 12: Correlation between $\lambda_{s}$ and Innovation Using World Bank Data for Brazil

\begin{tabular}{lcc}
\hline$(1-e)_{s}$ & Process $W B_{f}$ & Product $W B_{f}$ \\
\hline$\lambda_{s}$ & -0.0893 & 0.0105 \\
\hline Notes: For the estimations we have used 1397 firms for which we could combine firm-level data with the \\
Khandelwal (2010) classification of goods. The World Bank Survey for Brazil was conducted in year 2003. \\
\hline
\end{tabular}




\subsection{Data Appendix}

Figure 6: $\triangle T R E R_{i}$ for Industries with Different Degrees of Product Differentiation

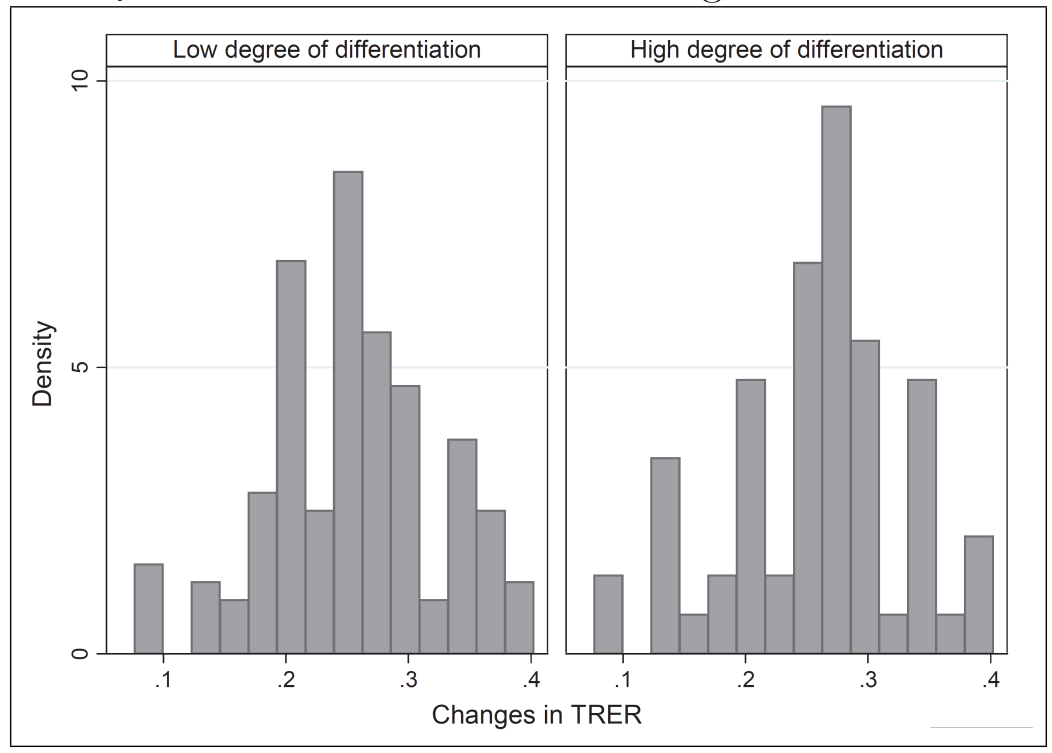

Table 13: Summary Statistics of Main Variables

\begin{tabular}{lccc}
\hline \multicolumn{1}{c}{ Variable } & Obs & Mean & Std. Dev. \\
\hline FDI $f, t=0$ & 3,070 & 0.184 & 0.388 \\
Skills $_{f, t=0}$ & 3,070 & 0.120 & 0.130 \\
$\log$ Ndestinations $_{f, t=0}$ & 3,070 & 1.543 & 1.036 \\
$\log$ Nproduct $_{f, t=0}$ & 3,070 & 1.476 & 1.167 \\
$\log$ Nworkers $_{f, t=0}$ & 3,070 & 5.503 & 1.180 \\
$\Delta \log$ Nworkers $_{f}$ & 3,070 & 0.039 & 0.463 \\
$\lambda_{s}$ & 3,070 & 1.73 & 0.21 \\
$\lambda_{f}$ & 3,070 & 1.74 & 0.60 \\
ShDiff $_{s}$ & 3,070 & 0.73 & 0.12 \\
$\Delta$ TRER $_{i}$ & 3,070 & 0.256 & 0.076 \\
TRER $_{i t}$ & 6,140 & 0.608 & 0.138 \\
\hline
\end{tabular}


